\title{
Pathophysiological and Immunological
}

\section{Aspects of Meconium Aspiration \\ Syndrome}

\section{Bodil Salvesen}

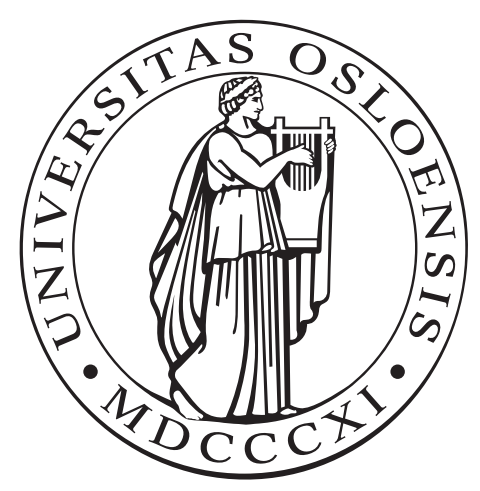

Department of Pediatric Research

Institute of Immunology

Faculty of Medicine

University of Oslo

Rikshospitalet University Hospital

Norway 
(C) Bodil Salvesen, 2010

Series of dissertations submitted to the Faculty of Medicine, University of Oslo No. 944

ISBN 978-82-8072-390-1

All rights reserved. No part of this publication may be reproduced or transmitted, in any form or by any means, without permission.

Cover: Inger Sandved Anfinsen.

Printed in Norway: AiT e-dit AS.

Produced in co-operation with Unipub.

The thesis is produced by Unipub merely in connection with the thesis defence. Kindly direct all inquiries regarding the thesis to the copyright holder or the unit which grants the doctorate. 


\section{TABLE OF CONTENTS}

PREFACE... .5

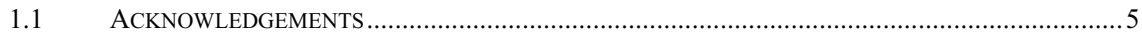

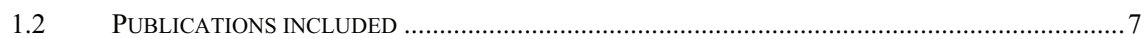

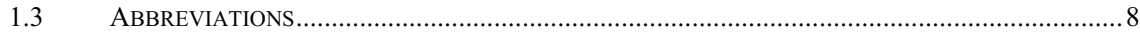

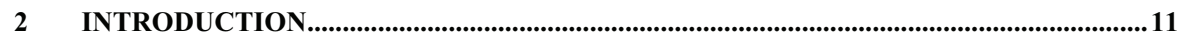

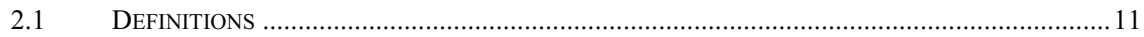

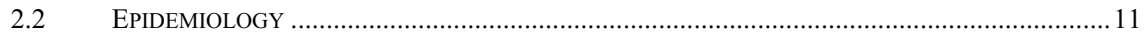

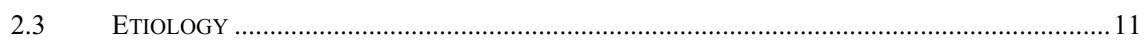

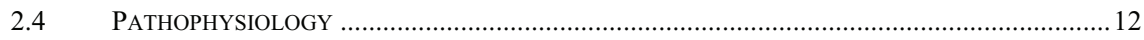

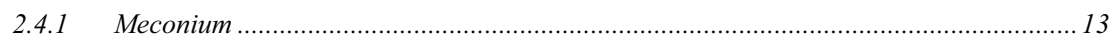

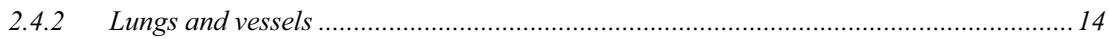

2.4.3 Surfactant displacement and inactivation.............................................................. 15

2.4.4 Meconium aspiration syndrome and inflammation ................................................... 15

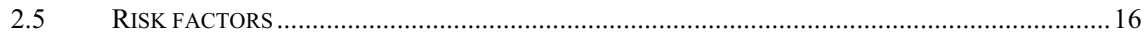

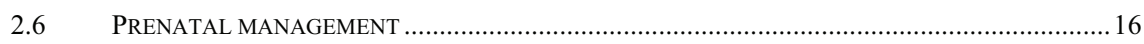

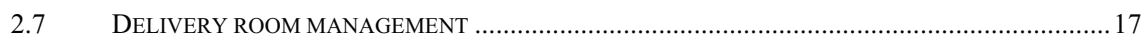

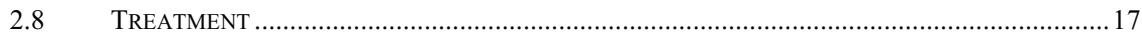

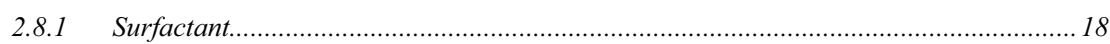

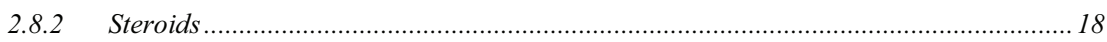

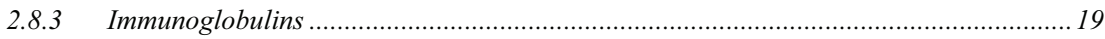

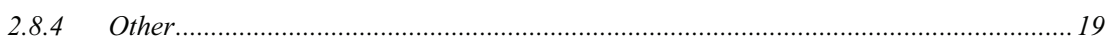

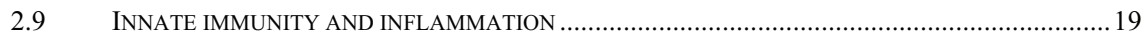

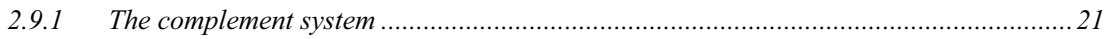

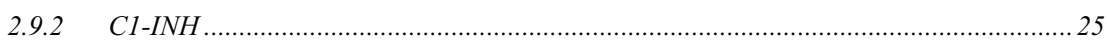

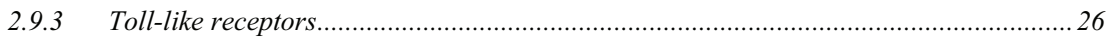

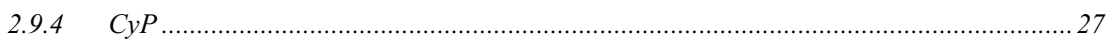

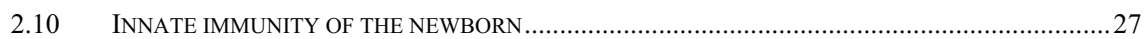

2.11 PREVIOUS STUDIES PERFORMED ON MECONIUM AT THE INSTITUTE OF IMMUNOLOGY AND THE

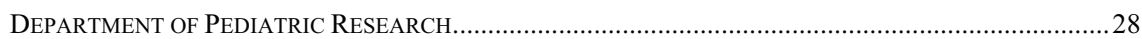

3 AIMS OF THE STUDY ........................................................................................................29

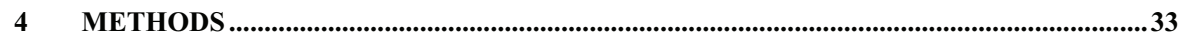

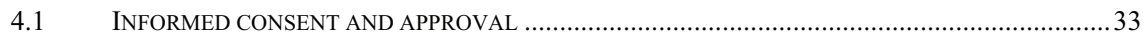

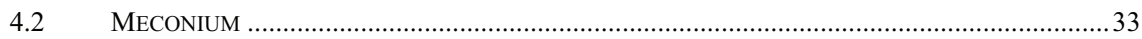

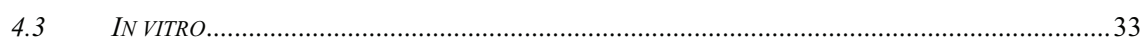

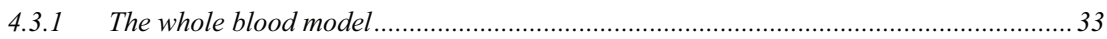

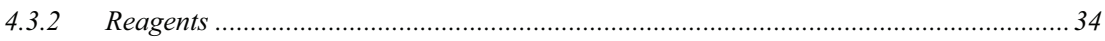




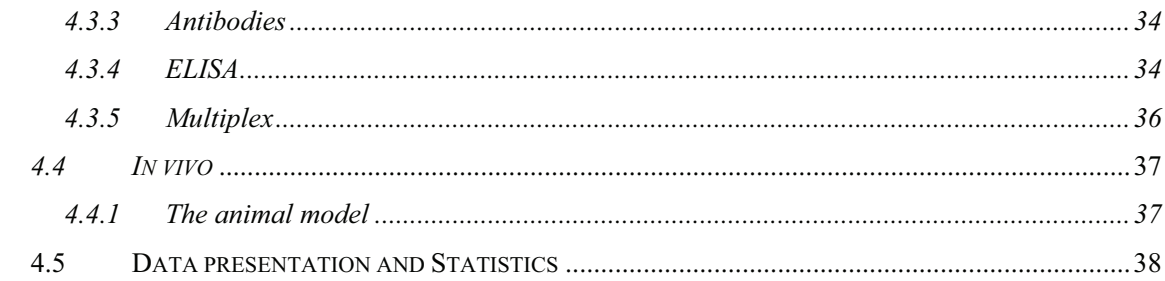

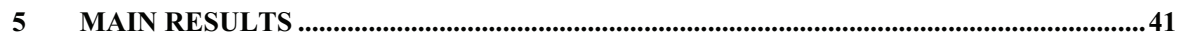

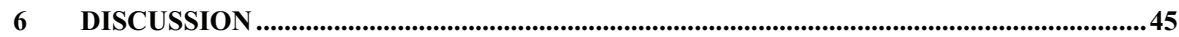

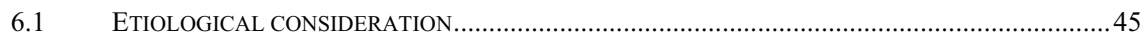

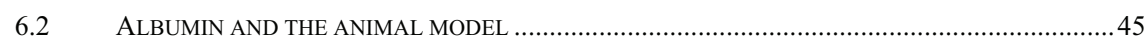

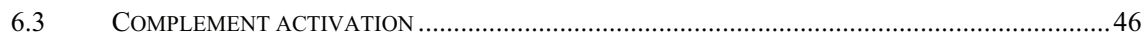

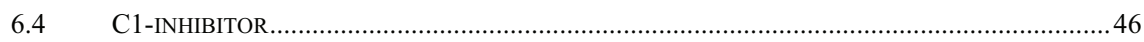

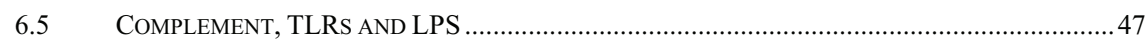

6.6 LPS AND ENDOGENOUS ACTIVATION OF THE INFLAMMATORY RESPONSE ............................48

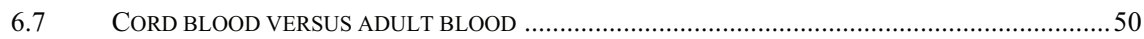

6.8 TESTING OF PORCINE COMPLEMENT ACTIVITY ………........................................................ 50

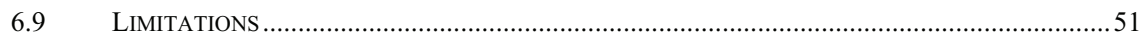

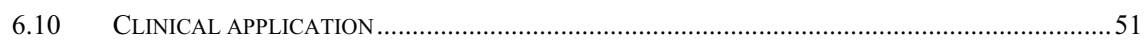

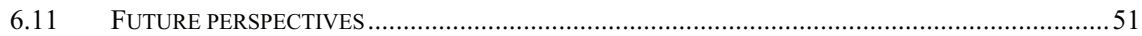

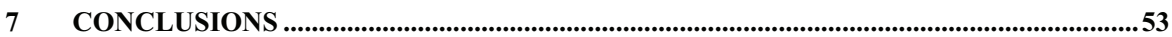

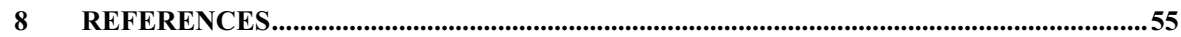

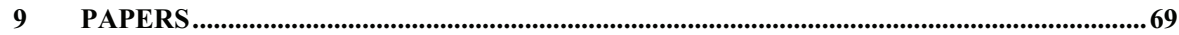




\section{PREFACE}

\subsection{Acknowledgements}

The present work was carried out at the Institute of Immunology and the Department of Pediatric Research, Rikshospitalet and University of Oslo during the years 20052008. The project was financially supported by the Research Council of Norway.

I want to thank my two supervisors for the introduction to medical research. Professor Ola Didrik Saugstad offered me an office at the Department of Pediatric Research, introduced me to pediatric research and encouraged me to participate at international meetings and present my research. Professor Tom Eirik Mollnes introduced me to immunology and the complement system. All in vitro experiments are performed in his lab. His enthusiasm and ability to find opportunities even if the experiments looked disappointing was encouraging.

Anne Pharo, chief technician in the "Complement Research Group" at the Institute of Immunology has provided excellent advice, kindness and patience. She has also performed some analyses in my last two papers while I was in Bergen.

Dr.med Albert Castellheim introduced me to Professor Mollnes. Albert and dr.med Paal HH Lindenskov also taught me the experimental model of meconium aspiration syndrome in newborn pigs.

Technician Julie Katrine Lindstad performed some analyses in papers IV and V. Former technician of our group Merethe Sanna Borgen performed some analyses in paper I. Technicians Grethe Bergseth and Judith Ludviksen at the "Complement Research Group" in Bodø, helped with analyses of the complement activation products in paper II.

I am very grateful to Professor emeritus Morten Harboe as a co-author of paper II and for sharing his great knowledge of immunology, his support and encouragement. Professor Erik Waage Nielsen contributed with his knowledge of C1-inhibitor as a 
second author in paper II. He has also given me important advice about statistics and computer technology. I also like to thank my other co-authors, PHD Michael Fung, PHD Jørgen Stenvik, Professor Terje Espevik and PHD Carlo Rossetti

The animal experiments were performed at the Institute for Surgical Research. Director Professor Ansgar Aasen, and chief nurse Vivi Bull Stubberud provided excellent working facilities and equipment. Many thanks to Roger Ødegård for assisting me in surgery of the animals used in the in vivo studies

Chief veterinarian Dag Sørensen and engineer Randi Værømoen at the Department of Comparative Medicine deserves many thanks for their assistance with delivery of the newborn pigs.

Many thanks to my colleagues at the Department of Pediatric Research and in the "Complement Group" at the Institute of Immunology and my colleagues at the Department of Pediatrics and the Neonatal Intensive Care unit, Barneklinikken, Rikshospitalet were I have been employed during my years of research. Finally many thanks to my friends and family. 


\subsection{Publications included}

1. Salvesen, B., Mollnes, T.E., Saugstad, O.D.

"Albumin lavage does not improve the outcome of meconium aspiration syndrome"

Journal of Maternal, Fetal and Neonatal Medicine, 2008; 10:719-25

2. Salvesen, B., Nielsen, E. W., Harboe, M., Saugstad, O. D., \& Mollnes, T. E. "Mechanisms of complement activation and effects of $\mathrm{C} 1$-inhibitor on the meconium-induced inflammatory reaction in human cord blood", Molecular Immunology, 2009; 46:688-694.

3. Salvesen, B., Fung, M., Saugstad, O. D., \& Mollnes, T. E. "Role of Complement and CD14 in Meconium-Induced Cytokine Formation" Pediatrics, 2008; 121: e496-e505.

4. Salvesen, B, Steinvik, J., Rossetti, C., Saugstad, O.D., Espevik, T., Mollnes, T.E. "Meconium-induced Release of Cytokines is mediated by the TRL4/MD-2 Complex in a CD14-dependent Manner" Submittet.

5. Salvesen, B. \& Mollnes, T. E.

"Pathway-specific complement activity in pigs evaluated with a human functional complement assay",

Molecular Immunology, 2009; 46:1620-1625. 


\subsection{Abbreviations}

aHUS - recurrent atypical haemolytic uremic syndrome

AMD - age-related macular degeneration

ANOVA - analysis of variance

$\mathrm{AP}$ - alternative pathway

APC - antigen presenting cell

AU - arbitrary units

Basic FGF - fibroblast growth factor

C1-INH - C1-inhibitor

$\mathrm{CI}$ - confidence interval

$\mathrm{CP}$ - classical pathway

CyP - cyanobacterial product

DAMPs - damage/danger associated molecular patterns

ECD - extracellular domain

ECMO - extracorporeal membrane oxygenation

EDTA - ethylenediaminetetraacetic acid

EIAs - enzyme immunoassays

ELISA - enzyme-linked immunosorbent assay

FDC - follicular dendritic cell

$\mathrm{FiO}_{2}$ - fraction of inspired oxygen

GA - gestational age

G-CSF - granulocyte colony-stimulating factor

GM-CSF - granulocyte macrophage colony-stimulating factor

HFV - high frequency ventilation

IgG - immunoglobulin G

$\mathrm{IL}$ - interleukin

ILCOR - The International Liaison Committee on Resuscitation

IFN- $\gamma$ - interferon-gamma

IP-10 - interferon-inducible protein

LP - lectin pathway

LPS - lipopolysaccharide

$\mathrm{mAb}$ - monoclonal antibody

MASP - mannose binding lectin associated protease 
MAS - meconium aspiration syndrome

MASF - meconium-stained amniotic fluid

MBL - mannose binding lectin

MCP-1 - monocyte chemotactic protein-1

MD-2 - myeloid differentiation protein-2

MIP-1 $\alpha$ - macrophage inhibitory protein- $1 \alpha$

MPGN - membranoproliferative glomerulonephritis

NCPAP - nasal continuous positive end-expiratory airway pressure

NFא-B - nuclear factor kappa-light-chain enhancer of activated B-cells

NHS - normal human serum

NLRs - NOD-like - nucleotide-binding oligomerization-domain protein like receptors

$\mathrm{NO}$ - nitrogen oxide

NPS - normal pig serum

OI - oxygenation index

PAMPs - pathogen associated molecular patterns

PBS - sterile phosphate-buffered saline

PDGFbb - platelet derived growth factor bb

PEEP - positive end expiratory pressure

PIP - peak inspiratory pressure

PLD - partial lipodystrophy

PPHN - persistent pulmonary hypertension of the newborns

PRR - pathogen recognition receptor

RANTES - regulated upon activation, normal T cell expressed and secreted

ROS - reactive oxygen species

RLRs - RIG-1-like receptors

SLE - systemic lupus erythematosus

TCC - terminal sC5-9 complement complex

TIR - TOLL/IL-1 receptor

TLR - toll like receptor

TNF- $\alpha$ - tumor necrosis factor alpha

VCP- vaccinia complement control protein

VEGF - vascular endothelial growth factor

VI - ventilation index 


\section{INTRODUCTION}

\subsection{Definitions}

Meconium aspiration syndrome (MAS) is defined according to Cleary and Wiswell as "respiratory distress in an infant born through meconium-stained amniotic fluid (MSAF) whose symptoms cannot otherwise be explained" (1). Severe MAS is classified as cases that need mechanical ventilation.

\subsection{Epidemiology}

In the developed world, the incidence of MAS is low, in UK about 2 per 1000 live births (2). This incidence is considerably higher in the developing world, 4-11 per 1000 in South Africa (3). In a cohort of 176000 neonates born from 1973-1987, Wiswell reported an overall frequency of MASF in $12.5 \%$ of all deliveries. Of those born through MASF, approximately 2-5\% developed MAS and more than $4 \%$ of them died (4). In a cohort from Australia and New Zealand (1995-2002) the incidence of severe MAS was 0.43 per 1000 live births (5). There was an overall decrease in the incidence to 0.35 per 1000 in 2002. Between 36 and 40 weeks gestational age (GA), the incidence varied between $0.24-0.46$ per 1000 compared to an incidence of 1.42 per 1000 at 42 weeks and beyond. Mortality in the severe MAS cohort was $2.5 \%$. Yoder et al reported a decreased incidence of MAS from 5.8\% (1990-1992) to $1.5 \%$ (19971998) in meconium-stained infants $>37$ weeks in a prospective study (6). Significant changes in obstetrical characteristics were reported, but the only change in neonatal characteristics was a $33 \%$ decrease in births $>41$ weeks.

\subsection{Etiology}

Aspiration of meconium was earlier considered to be a postnatal event caused by aspiration of meconium at the first breath (7). Suction of the trachea and oropharynx at delivery decreased the incidence of mild and moderate MAS (8;9). MAS is no longer considered to be a postnatal disorder caused by postnatal aspiration, but rather 
a disorder with antepartum, intrapartum and neonatal causes (10). Now, the hypothesis is that aspiration of meconium may occur in utero, during or after delivery, and that a chronic in utero insult may be responsible for severe MAS $(11 ; 12)$. Thureen et al found that in eight autopsies, pulmonary and placental changes suggesting in utero onset of a disease with subacute or chronic duration (13). This in concordance with the observed effects by Wiswell et al showing no effect on the incidence of MAS if the infant was intubated and tracheal suction performed in the delivery room, compared to infants only treated if they developed symptoms (14). Vain et al showed that routine intrapartum oropharyngeal and nasopharyngeal suctioning of termgestation infants born through MSAF did not prevent MAS (15).

Ghidini et al reviewed the literature and concluded that severe MAS is caused by chronic asphyxia or intrauterine infection (12).

\subsection{Pathophysiology}

MAS has a complex not well defined pathophysiology (1). Several factors are involved including (1) direct toxicity of meconium and its constituents resulting in alveolar and parenchymal inflammation with release of inflammatory mediators, edema and protein leakage into the alveoli, tissue necrosis and apoptosis in the lung and ulcerations of the umbilical cord, (2) airway obstruction caused by meconium, edema fluid, protein exudates and blood cells (3) altered elastic forces in the lungs resulting in increased resistance and decreased compliance, (4) inactivation and dysfunction of surfactant caused by meconium, protein and inflammatory cells leading to atelectases, air trapping, pneumothorax, right-to-left shunting, (5) in utero hypoxemia leading to pulmonary vascular remodelling and lung parenchymal changes, and vasoconstriction of placental and umbilical vessels. Ventilationperfusion mismatch contribute further to acidosis, hypercapnia, and hypoxemia.

Meconium-stained amniotic fluid is rarely detected before 37 weeks of gestation (16), but occurs in more than one third of pregnancies lasting longer than 42 weeks (17). Prenatal passage of meconium is normally prevented by lack of intestinal peristalsis caused by low motilin levels (18), tonic contraction of the anal sphincter and a terminal cap of viscous meconium. 
Intrauterine infections may induce a fetal inflammation syndrome with activation of neutrophils, macrophages, cytokines and the complement system, resulting in tissue destruction. The incidence of clinical chorioamnionitis is significantly higher in the presence of severe than mild MAS (19). Among women in preterm labor, the prevalence of positive amniotic fluid cultures after amniocentesis is significantly higher in those with MASF compared to those with clear fluid (20). Histological evidence of acute placental inflammation is present in a majority of cases of severe MAS (21), supporting the fact that intrauterine infections may underlie or contribute to a proportion of cases of severe MAS. This is supported by the lack of studies that directly correlate the severity of MAS with the amount of meconium aspirated, the thickness of meconium, and the duration of the exposure to meconium (22).

The fact that the incidence of severe MAS is higher in post-term infants $(\mathrm{RR}=3.1$; 95\% CI, 2.6-3.7) (23), that placental ischemic changes suggesting long compromise of utero-placental bloodflow (13), that pulmonary vascular hypertrophy found in almost all cases of severe MAS also may be found in the absence of meconium passage (24), and that chronic in utero hypoxia may lead to persistent pulmonary hypertension of the newborns (PPHN) also in cases without meconium passage (24), supports that severe MAS may be caused by chronic asphyxia.

\subsubsection{Meconium}

Meconium is detected in the gastrointestinal tract of the fetus as early as 10-16 weeks of GA and represents material accumulated during fetal life. It is blackish-green, odourless and varies in amount from 60 to $200 \mathrm{~g}$ (25). Meconium consists of $72-80 \%$ water (26). Meconium contains secretions from salivary and intestinal glands like mucus, bile and bile acids, fatty acids and steroids from the gut, cellular debris, lanugo hair, components of vernix caseosa, amniotic fluid, and blood (27). Meconium may also contain various amounts of proinflammatory substances including TNF- $\alpha$, IL-1 $\beta$, IL-6 and especially IL-8 (28).

Meconium and amniotic fluid have been considered to be sterile as well as the gastrointestinal tract of the normal fetus (29). Yet the prevalence of positive amniotic fluid cultures was significantly higher in women with meconium-stained amniotic 
fluid and intact membranes than in women with clear fluid (20). Meconium may contain variable amounts of lipopolysaccharide (LPS) under certain conditions. First, meconium from normal deliveries may be contaminated by LPS during collection and preparation, influencing the results from in vitro and in vivo experimental studies using normal meconium. Second, fetal membranes, even from deliveries by cesarean section at term, had microbial organisms present (70\%) although only less than $25 \%$ showed inflammatory cells present (30). Third, intrauterine infections may increase bacterial and LPS load. Fetal membranes obtained after premature labor or after prolonged premature rupture of membranes are mainly positive for bacteria deep within the membranes and for inflammatory cells in amnion or chorion (30). Jimenez et al identified Enterococcus fecalis in 17 of 21 meconium samples from healthy newborns and Staphylococcus epidermidis in 10 of the samples (31). Escherichia coli and Enterobacter spp. were also detected. Labelled E.fecium given orally to pregnant mice was isolated from aseptically collected meconium from fetuses delivered by cesarean section one day before predicted labor. Meconium has extremely high surface tension (32). In vitro meconium is chemotactic to neutrophils (33) and possibly also vasoactive (34).

\subsubsection{Lungs and vessels}

Respiratory symptoms may be secondary to meconium aspiration in utero or at birth, or to alterations in the pulmonary vasculature secondary to asphyxia or to meconium itself (26). MAS is believed to be caused by a combination of mechanical blockage of the small airways and chemical pneumonitis induced by meconium particles aspirated $(24 ; 35)$. Aspiration of meconium may cause partial obstruction of the airways with air trapping and atelectases and development of air leaks or complete obstruction with alveolar collapse and ventilation-perfusion mismatch (36). Estimated risk of pneumothorax is $15-33 \%$ (1). Mechanical dysfunction of lungs is more severe during the early phase of MAS with lower dynamic and specific lung compliance and increased airway resistance (37).

Vasospasms, hypertrophy of the pulmonary musculature, and pulmonary hypertension lead to right-to-left shunting through the foramen ovale and ductus arteriosus. MAS is the most common cause of persistent pulmonary hypertension of the newborns 
$(38 ; 39)$ with abnormally constricted pulmonary vasculature. About two thirds of infants with PPHN have meconium-stained amniotic fluid and about half of the infants with PPHN have the concurrent diagnosis of meconium aspiration syndrome. Meconium injury trigger postnatal release of vasoactive mediators like endothelin-1, thromboxane-A2 and prostaglandin E2 (40;41). Meconium induced a dose-dependent oxidative burst in neutrophils with increased levels of vasoactive peptides $(42 ; 43)$.

\subsubsection{Surfactant displacement and inactivation}

Meconium, protein, and inflammatory cells inactivate surfactant function and alters surfactant production (44-46). Meconium displaces surfactant from the alveolar surface and inhibits surfactant function reducing its ability to reduce the surface tension. Bronchial lavage fluid from infants with MAS, contained increased levels of albumin, total protein and membrane-derived phospholipids compared to controls. The inhibition of surfactant in the alveolar spaces may be mediated by meconium, plasma proteins, edema fluid and haemoglobin.

\subsubsection{Meconium aspiration syndrome and inflammation}

Toxic effects of meconium trigger inflammation in the lungs $(39 ; 47)$. Activated neutrophils and macrophages are detected in the lung parenchyma and alveoli only hours after meconium aspiration (48). Meconium activates the complement system both in vitro (49) and in vivo in an experimental model of MAS in newborn pigs (50). The latter is associated with a systemic inflammatory response with increased formation of proinflammatory cyokines. The release of proinflammatory cytokines may directly injure the lung parenchyma resulting in vascular leakage causing pneumonitis and pulmonary edema $(51 ; 52)$. Most proinflammatory cytokines and chemokines measured, as well as the anti-inflammatory cytokine IL-10, were significantly elevated in sera from neonates with MAS (53).

Meconium-induced inflammatory lung injury is associated with respiratory epithelial apoptosis in several animal models $(52 ; 54)$. Meconium activates the pulmonary reninangiotensin system shown by an increase in angiotensinogen mRNA associated with 
apoptosis and cytokine release. Angiotensin-II receptor, which is expressed in several cell types in the newborn lung, including bronchial and alveolar epithelium and bronchial and vascular smooth muscle, are up-regulated after meconium exposure (55).

\subsection{Risk factors}

Signs of fetal compromise like abnormalities of fetal heart tracings and/or low Apgar scores increase the risk of MASF (56) and of MAS in the meconium stained infant (6). However, normal acid-base status at delivery is present in many cases of severe MAS, suggesting that either a pre-existing injury or nonhypoxic mechanisms also must be involved (11).

There is an increased risk of MAS in Africans (57) and Pacific Islanders (58), and also in afro-Americans compared to other Americans.

Advanced gestation is a risk factor of both MASF and MAS (17). Risk factors for developing respiratory distress in infants born through meconium-stained amniotic fluid are male gender, few prenatal visits, abnormal fetal heart tracing, oligohydramnios, cesarean delivery, and low Apgar score (59)

\subsection{Prenatal management}

Transcervical intrapartum infusion of saline into the amniotic cavity has been proposed to reduce the risk for MAS. The proposed mechanism is mechanical cushioning of the umbilical cord to prevent recurrent umbilical compressions leading to fetal acidosis and dilution of meconium to reduce mechanical and inflammatory effects (60). A systematic review of the literature by Xu concluded that only in settings with limited peripartum surveillance and where complications are common, amnioinfusion appeared to reduce the risk of MAS (60). 


\subsection{Delivery room management}

Carson at al demonstrated in 1976, a decreased incidence of MAS after intrapartum oropharyngeal suction, that is suction after delivery of the head (61). Vain et al showed that routine intrapartum oropharyngeal and nasopharyngeal suctioning of term-gestation infants born through MSAF did not prevent MAS (15). Wiswell et al showed no effect on the incidence of MAS if the infant was intubated and tracheal suction performed in the delivery room, compared to infants only treated if they developed symptoms (14). Routine intrapartum oropharyngeal and nasopharyngeal suctioning of term-gestation infants born through MSAF or routine endotracheal intubation at birth in vigorous meconium-stained babies, is not recommended $(14 ; 15 ; 47 ; 62)$.

Still the the International Liaison Committee on Resuscitation (ILCOR) recommends tracheal suction of the depressed meconium-stained infant immediately post-partum and before stimulation, although this is not evidence-based.

\subsection{Treatment}

Infants at risk for MAS with respiratory distress must be monitored closely and supportive treatment must be provided if necessary. In the Australian /New Zealand cohort there was an increasing use of surfactant, high frequency ventilation (HFV) and inhaled Nitric Oxide from 1995-2002 (5). However, the amount of infants who needed to be put on extracorporeal membrane oxygenation (ECMO) (1.1\%) did not change during the study period.

The amount of ventilatory support needed, depends on the amount of respiratory distress. Some infants only need oxygen, some nasal continuous positive endexpiratory airway pressure (NCPAP). HFV treatment minimizes barotraumas. HFV improved oxygenation in an experimental model of MAS in rats especially when combined with surfactant (63). Carter et al investigated rescue with HFV in ECMO candidates in newborns with respiratory distress. Almost 50\% responded to HFV 
alone, but amongst the non-responders there were a lot of infants with MAS (64). Experimental data suggest that HFV is an effective ventilator mode to improve gas exchange in MAS.

\subsubsection{Surfactant}

Bolus surfactant therapy has been studied in several animal and human models. Two randomized controlled trials of bolus surfactant have been conducted $(65 ; 66)$. The studies were different, but data from both studies pooled together, suggest that surfactant in repeated doses in ventilated infants with MAS, may be associated with a reduction in the need for ECMO.

Therapeutic lung lavage has been thoroughly investigated in several animal models. Few human randomized controlled studies are yet published. Saline, perfluorocarbon, full-strength and diluted surfactant are lavage fluids used in animal studies (67). Lung lavage using surfactant improved gas exchange compared to bolus surfactant. Oxygenation seemed to improve and the incidence of pneumothorax seemed reduced in some studies (67). The only prospective randomized controlled trial performed by Wiswell et al enrolling 22 infants, found no clear differences between lavaged individuals and controls in terms of air leak, duration of ventilation, and the need for ECMO (68).

A Cochrane review published in 2007 concludes that surfactant administration may reduce the severity of respiratory illness and decrease the number of infants with progressive respiratory failure requiring support with ECMO, but the relative efficacy of surfactant therapy compared to or in conjunction with other approaches to treatment, including inhaled nitric oxide, liquid ventilation, surfactant lavage and high frequency ventilation remains to be tested (69).

\subsubsection{Steroids}

Animal studies with corticosteroids have shown promising results (70;71). A

Cochrane review of two small randomized controlled trials failed to demonstrate 
improved outcome in duration of ventilation, air leaks or mortality (72). Infants treated with corticosteroids actually required supplemental oxygen therapy for a longer period. Salvia-Roigés combined surfactant lavage with dexamethasone in a small human study. Oxygenation significantly improved (73). TNF- $\alpha$ levels in tracheal aspirates were suppressed with use of steroids in newborns with MAS (74) .

\subsubsection{Immunoglobulins}

Intravenous immunoglobulins in a pig-model of MAS improved pulmonary hypertension and oxygenation, but in lung tissue of animals pre-treated with immunoglobulins, neutrophil accumulation was increased (75).

\subsubsection{Other}

Pre-treatment with captopril, an angiotensin converting enzyme inhibitor, significantly inhibited meconium-induced lung cell death and cytokine expression in newborn rabbit lungs $(76 ; 77)$. Addition of hyaluron, a substance natural occurring in alveolar fluid, to surfactant improved surface tension in the alveoli of rats in the presence or absence of meconium (78). CC10, clara cell protein is an antiinflammatory agent that may inhibit phospholipase A2. CC10 reduced the amount of TNF- $\alpha$ in bronchial lavage fluid in an experimental model of MAS in pigs (79).

\subsection{Innate immunity and inflammation}

Innate immunity is an ancient form of host defence against infection and danger signals and exists probably in all multicellular organisms (80). The innate immune system is also involved in several normal physiological processes like tissue remodelling during development and after damage, transport of blood lipids, and scavenging of apoptotic cells (81). Macrophages, dendritic cells, polymorph nuclear leukocytes and humoral factors like complement proteins, coagulation factors and collectins recognizes tissue-derived signals as well as pathogens. Innate immunity recognition is mediated by receptors which specificity is genetically predetermined. The innate immune system recognizes highly conserved structures present on large 
numbers of microorganisms referred to as pathogen-associated molecular patterns (PAMPs) (82). That is bacterial LPS, peptidoglycan, lipothecoic acids, mannan, zymosan, double stranded RNA, bacterial DNA, and glucans (82). Host-derived immunostimulators like hyaluronon, heat-shock proteins, surfactant proteins, IFN- $\alpha$, uric acid, fibronectin, $\beta$-defensin and cardiolipin also signal through the same receptors as PAMPs, originally termed damage-associated molecular patterns (DAMPs) $(81 ; 83)$. Recent years has the abbreviation DAMP, alternatively been used as "danger-associated molecular patterns", covering danger signalling of both endogenous and exogenous ligands.

The pattern-recognition-receptors (PRRs) are expressed on many effector cells of the innate immune system as macrophages, dendritic cells and B cells (80) and also on most non-immune innate cells like epithelial cells. PRRs and soluble pattern recognition molecules are innate sensors that discriminate self from non-self and damaged or modified self, and link innate to adaptive immunity (84). The effector cells are triggered immediately to perform their specific response as soon as the PAMP binds to the receptor. PRRs are involved in internalization of microbes by phagocytes (soluble PRRs and endocytic receptors), cell activation (signalling PRRs) and also recognition of dying cells (i.e. modified self) (84). PRRs are typically Tolllike receptors (TLRs), nucleotide-binding oligomerization-domain protein like receptors (NOD-like receptors (NLRs)), and RIG-1-like receptors (RLRs), whereas soluble recognition molecules include collectins like mannose-binding lectin (MBL), ficolins, C-reactive protein (CRP), C1q, and natural immunoglobin M (IgM) (85). MBL is a well known recognition molecule. It is a calcium-dependent lectin which binds microbial carbohydrates to initiate the lectin pathway of complement activation. It may bind to carbohydrates on Gram-positive and Gram-negative bacteria, yeast and some viruses and parasites (86). Recognition molecules mediate microbial opsonisation, complement activation and phagocytosis (87).

The TLRs belong to a family of type 1 transmembrane glycoproteins that recognizes structural patterns on bacteria, fungi, and viruses (87). The complement system and TLRs, including the CD14-associated TLR4/MD-2 complex, are two important components of the innate immune system, which both act upstream and partly independently (88). They recognize exogenous and endogenous ligands. Recent 
studies have suggested several cross-talk mechanisms between the two systems (89). Activation of $\mathrm{C} 3 \mathrm{a}$ and $\mathrm{C} 5 \mathrm{a}$ receptors enhanced the TLR-induced formation of proinflammatory cytokines in mice (90). Complement and TLRs are also important regulators of adaptive immunity $(91 ; 92)$.

An inflammatory response triggered by infection or tissue injury results in the delivery of blood components (plasma and leukocytes) to the site of infection or injury (93). In bacterial infections receptors of the innate immune system (TLRs and NLRs) are triggered (94). An initial recognition of the infection is mediated by tissueresident macrophages and mast cells and results in the formation of several inflammatory mediators including chemokines, cytokines, vasoactive amines, eicosanoids, and products of proteolytic cascades. They elicit an inflammatory exudat locally. Plasma proteins and leukocytes, normally restricted to blood vessels, gain access. The activated endothelium allows selective extravasation of neutrophils which attempt to kill invading agents by releasing toxic content in their granules including reactive oxygen species (ROS), reactive nitrogen species, proteinase 3, cathepsin G and elastase (95). Collateral damage to host tissue is unavoidable. A successful inflammatory response results in elimination of the infectious agent followed by a repair and resolution phase. A controlled inflammatory response is beneficial, but may become detrimental if deregulated.

\subsubsection{The complement system}

The complement system is an important part of innate immunity. It defends the organism against pyogenic bacterial infections, bridges innate and adaptive immunity and disposes immune complexes and other products of inflammation (96).

The complement system consists of more than 30 different proteins in plasma or on cell surfaces and act as a cascade system of proteases. The complement system has three activating pathways; the classical pathway (CP), the lectin pathway (LP) and the alternative pathway (AP). Activation of all pathways result in cleavage of $\mathrm{C} 3$, but the initial activation of each pathway is unique. 


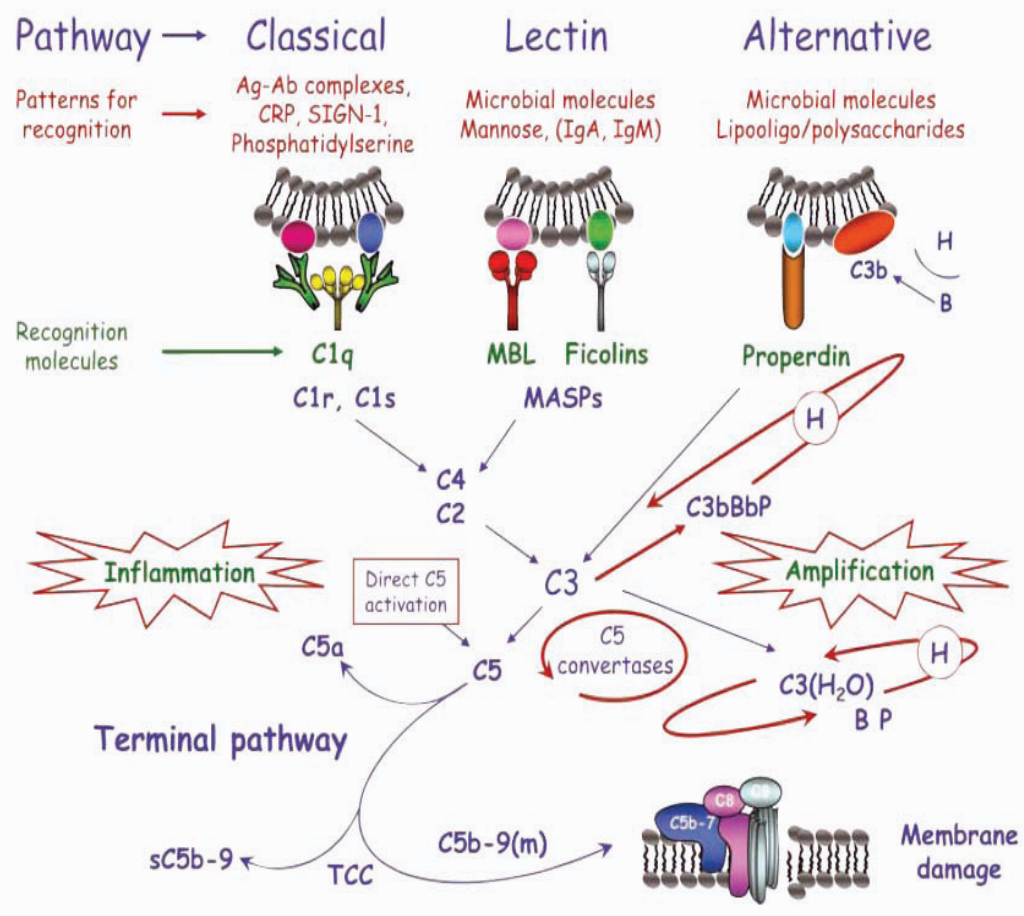

Fig 1: The complement system (Haboe M, Mollnes TE 2008, J .Cell. Mol. Med 12; 1074-83, with the permission of Blackwell Publishing Ltd)

The classical pathway is activated when $\mathrm{Clq}$ reacts with antibodies bound to their antigens, but may also react with other agents like C-reactive protein (CRP), SIGN$\mathrm{R} 1$ and phosphatidylserine (97). $\mathrm{C} 1 \mathrm{~s}$ then cleaves $\mathrm{C} 4$ to $\mathrm{C} 4 \mathrm{~b}$ which binds covalently to the bacterial surface and then cleaves $\mathrm{C} 2$ leading to the formation of the $\mathrm{C} 3$ convertase of the classical pathway, C4b2a (96). C4b2a cleaves $\mathrm{C} 3$ to $\mathrm{C} 3 \mathrm{~b}$ to form the C5 convertase $\mathrm{C} 4 \mathrm{~b} 2 \mathrm{a} 3 \mathrm{~b}$.

The lectin pathway is activated when MBL or ficolines recognizes carbohydrate structures on microbial surfaces and other sugars like N-acetyl-D-glucosamine (98;99). LP may also be activated by IgA and by structures on damaged endothelium (100). The MBL-associated serine proteases (MASPs) are triggered. MASP-2 leads to the formation of the LP convertase $\mathrm{C} 4 \mathrm{~b} 2 \mathrm{a}$, while MASP-1 under certain conditions may cleave C3 directly (96). 
The alternative pathway is initiated by the covalent binding of a small amount of $\mathrm{C} 3 \mathrm{~b}$ to hydroxyl groups on cell-surface carbohydrates and proteins, by foreign surfaces and also spontaneously by hydrolysis of the internal C3 thioester bond $(96 ; 101 ; 102)$. $\mathrm{C} 3 \mathrm{~b}$ binds factor $\mathrm{B}$ and forms the $\mathrm{C} 3 \mathrm{bB}$ complex. Factor $\mathrm{D}$ then cleaves factor $\mathrm{B}$ to form the alternative pathway convertase, $\mathrm{C} 3 \mathrm{bBb}$ (96). Properdin, the only known regulator of complement that amplifies activation, stabilizes the $\mathrm{C} 3 \mathrm{bBb}$ complex enhancing AP activation, but acts also as a recognition factor directly initiating AP activation (103). AP amplification plays an important role for the final effect of initial activation of CP and LP $(101 ; 104)$.

The C3 convertases then cleave C3. C3b binds covalently to the site of the complement activation, leading to the formation of $\mathrm{C} 5$ convertases. The $\mathrm{C} 5$ convertases then cleave $\mathrm{C} 5$. C5b initiates the formation of the C5b-9 terminal complement complex (TCC), frequently termed the membrane attack complex when inserted into a membrane. The terminal pathway proceeds by the assembly of $\mathrm{C} 7$ to C5b6 (100). Not dependent on the initial pathway of activation, the C5b-7 complex binds $\mathrm{C} 8$ and $\mathrm{C} 9$ creating a pore that penetrates the membrane leading to transmembrane leakage. If there is no membrane present and the activation occurs in the fluid phase, C5b-7 binds vitronectin and clusterin which are fluid phase regulators of the terminal pathway, leading to formation of the soluble TCC ( $\mathrm{sC} 5 \mathrm{~b}-9$ ).

The complement activation products $\mathrm{C} 3 \mathrm{a}, \mathrm{C} 4 \mathrm{a}, \mathrm{C} 5 \mathrm{a}$ are known as anaphylatoxins. Human C4a shows proinflammatory properties in guinea pigs by inducing smooth muscle contractions, increased vascular permeability and secretion of granules from platelets and $\mathrm{O}_{2}{ }^{-}$generation in macrophages (105). No evidence of anaphylactic effects is however seen in humans and no receptor for $\mathrm{C} 4 \mathrm{a}$ has been described. $\mathrm{C} 4 \mathrm{a}$ and C3a displayed antibacterial activities against bacterial isolates of Pseudomonas aeruginosa and Enterococcus faecalis (106). C3a mediates contraction of smooth muscles, chemotaxis and activates leucocytes, primarily eosinophils and mast cells and mediates increased vascular permeability (105). C5a is the most potent of the anaphylatoxins. C5a is a strong chemoattractant not only for neutrophils but also monocytes and macrophages, and is involved in the recruitment of inflammatory cells (macrophages, neutrophils, activated B- and T-lymphocytes, basophils and mast cells as well as the release of granulae-based enzymes and the formation of oxygen radicals 
$(91 ; 107)$. C5a may also modulate neutrophil and lymphocyte apoptosis, enhance expression of adhesion molecules and may activate the coagulation system. C3a and $\mathrm{C} 5 \mathrm{a}$ mediate several proinflammatory activities when bound to the $\mathrm{C} 3 \mathrm{a}$ receptor $(\mathrm{C} 3 \mathrm{aR})$ and the $\mathrm{C} 5 \mathrm{a}$ receptor $(\mathrm{C} 5 \mathrm{aR})$ respectively. $\mathrm{C} 5 \mathrm{a}$ exerts its effects through the receptors $\mathrm{C} 5 \mathrm{aR}$ and $\mathrm{C} 5 \mathrm{~L} 2$-receptors. $\mathrm{C} 3 \mathrm{a}$ and $\mathrm{C} 5 \mathrm{a}$ regulate vasodilatation, increase the permeability of small blood vessels and may induce contraction of smooth muscles (108).

Complement activation is controlled by fluid-phase and membrane bound inhibitors (96). The regulatory mechanisms are balanced so the deposition of complement proteins on normal cells and tissues are limited, while complement activation mainly takes place on the surfaces of invading pathogens.

Complement deficiencies may lead to severe diseases. Patients with a genetic complement deficiency, particularly of the classical pathway have increased susceptibility to systemic lupus erythematosus (SLE) and similar diseases (induction of tolerance and clearing of immune complexes), but there is also an increased activation of the complement system enhancing the inflammatory reaction (100). Complement deficiencies increasing the susceptibility to pyogenic infections are deficiencies of the opsonic activities of complement leading to increased susceptibility to pyogenic organisms, deficiencies that disturb the lytic activity of complement leading to increased susceptibility to neisseria infections, and deficiencies of the MBL pathway (96). Deficiency of C1-inhibitor (C1-INH) leads to a severe condition known as hereditary angioedema (100). Factor H deficiencies leads to severe kidney diseases because of uncontrolled activation of C3. Mutations and polymorphisms in factor $\mathrm{H}$ predispose to membranoproliferative glomerulonephritis type II (MPGN II), partial lipodystrophy (PLD), age-related macular degeneration (AMD), and atypical familial haemolytic uremic syndrome (aHUS) (109). Mutations in the phosphatidyl-inositolglycan class A gene, impairing the synthesis of the glycosylphosphatidyl anchor required for insertion of the complement regulatory proteins decay accelerating factor (DAF) and CD59, lead to paroxysmal nocturnal hemoglobinuri owing to the increased sensitivity of red blood cells to lysis. All diseases mentioned above are examples of innate (complement) reactivity against 
self-tissue under conditions where key complement inhibitors is absent or has an abnormal function.

The serum complement system also enhances the adaptive immune response. Activation of complement with release of cleavage products that interact with cell surface receptors found on several cell types provides a basis for the regulation of $\mathrm{B}$ and T-cell responses (85). Complement enhances B cell immunity by complement receptors CD21 (binds iC3b, C3dg and C3d) and CD35 (binds mainly $\mathrm{C} 3 \mathrm{~b}$ and $\mathrm{C} 4 \mathrm{~b}$ ). Follicular dendritic cells (FDCs) have a high expression of the complement receptors CD21 and CD35 which provides an effective mechanism of retention of C3-coated immune complexes within the lymphoid compartment. The complement system participates also in the regulation of T-cells by several mechanisms like direct opsonization of foreign antigens by antigen-presenting cell (APCs) and by modulating cytokine release.

\subsubsection{C1-INH}

C1-inhibitor is a serine protease inhibitor with a molecular mass of approximately $105 \mathrm{kDa}$. The plasma concentration is approximately $0.24 \mathrm{~g} / \mathrm{L}$ which corresponds to $1 \mathrm{U} / \mathrm{mL}$ (110). C1-INH has a protease inhibitory domain and a long heavily glycosylated amino terminal domain (111). It reduces activation of the classical complement pathway by binding to $\mathrm{C} 1 \mathrm{r}$ and $\mathrm{C} 1 \mathrm{~s}$ (112) and the lectin complement pathway by binding to the MBL-associated proteases, MASP-1 and MASP-2 (113) by protease inhibition. C1-INH may also inhibit activation of the alternative complement pathway by binding to $\mathrm{C} 3 \mathrm{~b}$, preventing the binding of factor $\mathrm{B}$. The latter does not depend on covalent binding to the protease (114).

C1-INH treatment has improved the outcome of inflammatory diseases including ischemia-reperfusion injury (myocardial, brain, skeletal muscle), hyper acute transplant rejection, vascular leak syndromes, as well as Gram negative bacterial sepsis and endotoxin shock $(115 ; 116)$. Activation of the complement system plays an important role in the pathogenesis of inflammatory diseases while the contact system probably is involved in mediation of damage (115). C1-INH's effects in sepsis and 
inflammatory disease are not only a result of covalent binding to proteases in the complement and contact system, since reactive center-cleaved, inactive C1-INH also is beneficial. These effects depend on non-covalent bindings to extracellular matrix components, C3b, selectins, Gram negative bacteria, and LPS (115). C1-INH concentrate has been administered safely over many years to patients suffering from inherited or acquired C1-INH deficiency (111).

\subsubsection{Toll-like receptors}

The classical PRRs are the Toll-like receptors (TLRs) which are type 1 transmembrane proteins with an intracellular signalling cytoplasmic TOLL/IL-1 receptor (TIR) domain and a leucine-rich repeat extracellular domain (ECD) responsible for the binding of a ligand (117). At least 12 different TLRs are described in mammals. TLR4 are together with TLR 1, 2, and 6 found on the plasma membrane of immune cells and recognize lipoproteins and lipoglycans on the surface of microbes. All TLRs except TLR 3 signal through the MyD88 dependent pathway leading to the activation of the NFKB gene-transcription program and the formation of proinflammatory cytokines. While immunostimulatory ligands or PAMPs (LPS, peptidoglycan, lipoarabinomanan) are microorganism- specific, host-derived immunostimulators like heparan sulphate, hyaluronon, heat-shock proteins, surfactant proteins, IFN- $\alpha$, uric acid, fibronectin, $\beta$-defensin and cardiolipin may signal through the same receptors $(81)$.

TLR4-mediated LPS recognition depend on a protein called myeloid differation protein 2 (MD-2) which forms a complex with the ectodomain of TLR4 (118). The CD14/TLR4/MD-2 complex recognizes lipopolysaccharides from gram-negative bacterial cell walls. MD-2 is a soluble protein which facilitates intracellular transport of TLR4 and regulates LPS-induced TLR4-clustering (119). MD-2 is a necessary cofactor for TLR4 in the detection of LPS and this process is greatly enhanced by CD14 and LPS-binding protein (LBP) (120;121), Soluble MD-2 can bind LPS directly with high affinity. This LPS/MD-2 complex forms a ligand that may activate TLR4 positive cells (122). MD-2 -/- mice do not respond to LPS (121). They survive endotoxin shock but are susceptible to Salmonella typhimurium infection. MD-2 is necessary for correct intracellular distribution and LPS-recognition of TLR4. 


\subsubsection{CyP}

The cyanobacterial product CyP is a LPS-related molecule derived from the cyanobacterium Oscillatoria planktothrix FP1. CyP acts as a specific TLR4/MD-2 antagonist, binds directly to MD-2 and competitively inhibits the binding of LPS and the downstream activation of NFKB (123). CyP protects mice from lethal LPSinduced shock. Delayed addition of CyP to dendritic cells preincubated with LPS, strongly inhibited signalling and cytokine formation by immediate downregulation of inflammatory cytokine mRNAs. Cyp is a potent antagonist of meningococcal LPS (124) and an efficient inhibitor of E.coli LPS (125).

\subsection{Innate immunity of the newborn}

Physiological demands of the fetal and neonatal immune systems need to protect against infection, including virus and bacterial pathogens at the maternal-fetal interface (126), avoid potential harmful pro-inflammatory/T helper 1-cellpolarization responses that may induce alloimmune reactions between mother and fetus, and to mediate the transition between the normally sterile intrauterine environment meeting the antigen-rich environment of the outside of the world, including primary colonization of the skin (127) and intestinal tract (128) by microorganisms. Limited exposure to antigens in utero and well described defects in neonatal adaptive immunity (129), results in the fact that newborns must rely on their innate immune system for protection to a certain extent. After birth the maturation of the immune system is age-dependant (130).

Basal TLR expression in full-term neonatal blood monocytes is similar to that in adult monocytes, but despite a higher concentration of monocytes at birth, addition of LPS to whole cord blood, resulted in diminished formation of TNF- $\alpha$ in cord blood compared to in adult blood (131). TLR-mediated formation of IL-6, IL-10 and IL-23 by neonatal monocytes, macrophages and myeloid DCs was actually enhanced in neonatal compared to adult cells (132). There was a high ratio of IL-6 to TNF- $\alpha$ production by mononuclear cells. According to Levy, neonatal monocytes express normal basal levels of membrane CD14 and TLR4, but the levels of CD14 may be 
low in prematures (133). After stimulation with LPS, neonatal neutrophils and monocytes demonstrate reduced expression of CD14 compared with adult cells. LPSinduced CXCL8 release were higher in neonatal peripheral blood leukocytes compared to adult (134). When pretreated with anti-TLR4 and anti-CD14, CD14 blockade induced an approximately 3-fold greater inhibition of CXCL8 compared with anti-TLR4. Neonates depended more on TLR4 for CXCL8 release.

Cord blood is known to contain approximately half the amount of complement components compared to adult blood $(135 ; 136)$.

\subsection{Previous studies performed on meconium at the Institute of Immunology and the Department of Pediatric Research}

Several studies have been performed at the Department of Pediatric Research and the Institute of Immunology concerning meconium and MAS. In an experimental model of MAS in newborn pigs Tølløfsrud et al hypothesized that lipids and bile acids in meconium were components responsible for meconium-induced lung injury (137). Albumin may bind these components. Albumin mixed with meconium before instillation, significantly reduced the detrimental effects of meconium in newborn pigs measured by oxygenation index (OI), ventilation index (VI) and dynamic compliance. If we look further into this paper, maximum oxygenation index was very low in both groups, 6.1 in the meconium group versus 3.1 in the meconium/albumin group. Both these values are so low that if not anaesthetized, neither group of pigs would probably need to be put on the respirator. Instillation of albumin as a rescue in the same model of MAS in newborn pigs, improved lung compliance (138).

Castellheim et al found meconium to be a potent activator of the complement system in vitro (49). Meconium activated the complement system also in vivo reflected by increased TCC in an experimental model of MAS in newborn pigs (50). Complement activation measured by TCC was followed by increased formation of proinflammatory cytokines as an indication of a systemic inflammatory response. The increased TCC was correlated with deteriorated lung function and increased mortality. 


\section{AIMS OF THE STUDY}

Meconium aspiration syndrome is a severe disease with a complex and not well defined pathophysiology. Despite ongoing research for interventional strategies, treatment of this disease is still only supportive.

In paper I, a continuum of earlier research performed at the Department of Pediatric Research, we used an in vivo model of MAS. We investigated if albumin-lavage would be an effective therapy. This treatment actually made the pigs worse. The animal model was far from optimal, since this disease has a complex, not well defined pathophysiology. We therefore found it necessary to learn more about the pathophysiology of MAS before trying to treat the disease. Our main aim became to investigate the pathophysiology of MAS with emphasize on activation of the innate immune system further.

Finally, if for instance complement inhibition or a combined inhibition of the CD14/TLR4/MD-2 complex would be an approach to decrease the inflammatory reaction in MAS, it would be interesting to know the immunity status of our research animals and also to follow the effect of our treatment, thereby paper $\mathrm{V}$.

\section{Paper I}

The first study was a continuum of earlier studies performed at the Department of Pediatric Research investigating the hypothesis of albumin as a neutralizer of toxic substances in meconium. The aim of this study was to explore whether instillation of albumin as a rescue after meconium and cleansing the airways by lavage would improve lung function and reduce the inflammatory response.

\section{Paper II}

Earlier studies have shown that meconium activates the complement system via the alternative pathway (49). New methods and reagents were now available. The aim of 
the first part of this study was to investigate the initial mechanisms of meconiuminduced complement activation.

C1-inhibitor (C1-INH) is a known inhibitor of classical and lectin pathway activation and may also reduce alternative pathway activation. C1-INH treatment has improved the outcome of several inflammatory diseases. In the second part of this study we therefore wanted to investigate to what extent C1-INH concentrate modified the meconium-induced inflammatory reaction in cord whole blood.

\section{Paper III}

The complement system and the CD14/TLR4/MD-2 complex are two main branches of innate immunity. The aim of this study was to investigate whether meconium, in addition to activing complement, also could induce CD14-mediated cytokine production and to what extent LPS was involved. We also compared the inflammatory effects of meconium in adult and cord whole blood.

\section{Paper IV}

Meconium activates complement and CD14 and may induce a systemic inflammatory response. Toll-like receptors are classical pattern-recognition receptors recognizing both exogenous and host derived ligands. The cyanobacterial product $\mathrm{CyP}$ is a potent LPS antagonist binding to the TLR4/MD-2 complex. The aim of this study was to investigate the role of the TLR4/MD-2 complex in meconium-induced inflammation by comparing the effect of MD-2 inhibition by $\mathrm{CyP}$ with CD14- inhibition in human whole blood and to investigate the involvement of CD14, MD-2, TLR4 and TLR2 in human transfected cell lines.

\section{Paper V}

Antibodies and tests used to evaluate medical research are not always applicable in animals. The human Wielisa test measures complement activity in human serum. The immunity status of our research animals may be useful in for instance sepsis research. The aim this study was to evaluate the applicability of the human Wielisa-test in pigs by investigating pig complement activity as well as monitoring the effect of 
complement inhibition, both in in vitro and in vivo models. We also aimed to use the test to see if pigs expressed variable lectin pathway activity, consistent with a certain percentage of MBL-deficiency. 


\section{METHODS}

\subsection{Informed consent and approval}

Informed consent was obtained from all donors and parents of healthy newborns donating cord blood. The studies were approved by the Norwegian Regional Ethical Committee. The experimental animal model was approved by the National Animal Research Authority (NARA) and the pigs were handled and cared for in accordance to guidelines.

\subsection{Meconium}

Meconium was collected with a wooden-spatula from diapers of 48 healthy newborns and stored in $50 \mathrm{~mL}$ propylene centrifuge tubes (Corning Inc., Acton, MA) at $-20^{\circ} \mathrm{C}$. The meconium was then thawed, pooled and processed in PBS and then freeze dried (HETO-FD3; Heto, Holten, Denmark). The meconium was reconstituted with PBS to a final concentration $100 \mathrm{mg} / \mathrm{mL}$ and then frozen in aliquots at $-20^{\circ} \mathrm{C}$ until the day of the experiment. No bacteria were detected after cultivation. The LPS content of the meconium used in paper I-IV was measured using a standard Limulus Ameboecyte Lysate Assay (LAL QCL-1000, Cambrex Bio Science, Walkersville, MD), and found to be $20 \mathrm{pg} / \mathrm{mg}$ meconium. The endotoxin or LPS content in meconium used in paper V, was analyzed in a Pyrochrome ${ }^{\circledR}$ Limulus Amoebocyte Lysate assay by an endpoint chromogenic method using a diazo-coupling assay kit. The LPS content in the meconium was found to be $30 \mathrm{EU} / \mathrm{mg}$ meconium or $3 \mathrm{ng}$ LPS per mg meconium.

\subsection{In vitro}

\subsubsection{The whole blood model}

The in vitro whole blood model using the highly specific thrombin inhibitor lepirudin (recombinant hirudin analog, Refludan $($ ) as an anticoagulant (139) has been developed in our laboratory. Lepirudin does not alter complement activation in 
contrast to other anticoagulants like EDTA, citrate and heparin. Lepirudin $50 \mu \mathrm{g} / \mathrm{mL}$ whole blood was used in all whole blood experiments.

\subsubsection{Reagents}

All materials and solutions in this study were endotoxin-free according to the manufacturers. Polypropylene tubes were NUNC cryotubes (Nalgene NUNC, Roskilde, Denmark). Sterile phosphate-buffered saline (PBS) was from Dulbecco (Paisley, United Kingdom), lepirudin (Refludan ${ }^{\circledR}$ ) from Hoechst (Frankfurt am Main, Germany), heparin from Løwens Kemiske Fabrik (Ballerup, Denmark), C1-INH concentrate (Cetor $\left.{ }^{\circledR}\right)$ from Sanquin CLB (Amsterdam, The Netherlands), human serum albumin and immunoglobulin $\mathrm{G}(\mathrm{IgG})\left(\right.$ Octagam $\left.{ }^{\circledR}\right)$ from Octapharma $\mathrm{AG}$ (Lachen, Switzerland). CyP was purified from the freshwater cyanobacterium Oscillatoria planktothrix FP1 by a phenol-guanidium thiocyanate-based method as described previously (123) and was a gift from Carlo Rossetti.

\subsubsection{Antibodies}

Mouse monoclonal antibodies blocking C2 (clone 175-26, IgG1) and factor D (clone 166-32, IgG1) and an isotype-matched control (clone G3-519, IgG1) were produced and purified under identical conditions (140;141). The combination of anti-C2 and anti-factor D efficiently block all three initial pathways of complement. Mouse antihuman CD14 (clone18D11; purified IgG1 and F(ab') 2 ) was purchased from Diatec (Oslo, Norway). Mouse anti-MBL monoclonal antibodies (mAbs) binding to different epitopes on MBL, were a gift from G.L.Stahl, Harvard Medical School. 3F8 (IgG1) inhibits MBL-dependent C3 deposition on mannan-coated plates (142) while 1C10 (IgG2b) is non-inhibiting (143).

\subsubsection{ELISA}

Several different enzyme-linked immunosorbent assays (ELISAs) exist (144;145). In the double antibody sandwich ELISA, an antibody is attached to the bottom of a well and provides antigen capture and specificity. Another antibody linked to an enzyme 
provides detection and an amplification factor. The wells are coated with a capture antibody; the plate is incubated with for instance serum or plasma containing the inflammatory mediator we want to measure. The detection antibody which is linked to an enzyme is added before adding the substrate and a color change appears.

In paper I, TNF $\alpha$, IL-1 $\beta$, IL-6, and IL-8 were analyzed using commercial available enzyme immunoassays, performed according to instructions provided by the manufacturer (R\&D Systems, Oxford, UK).

\subsubsection{TCC}

Complement activation was measured by quantification of the terminal sC5b-9 complex (TCC) using an enzyme-linked immunosorbent assay (ELISA) as previously described and later modified $(146 ; 147)$. The assay is based on a monoclonal antibody (aE11) highly specific for a neoepitope exposed in C9 when incorporated into TCC. Values are given in arbitrary units (AU) defined by a serum standard activated with zymosan and defined to contain $1000 \mathrm{AU} / \mathrm{mL}$.

\subsubsection{C1rs/C1-INH complexes, $C 4 d, C 3 b B b P$}

Enzyme immunoassays (EIAs) based on mAbs recognizing products of the different pathways, were used to measure complement activation. C1rs/C1-INH complexes reflecting CP activation, was quantified as previously described (148). C4d, reflecting $\mathrm{CP}$ and LP activation was measured using the Quidel C4d Fragment Enzyme Immunoassay (Quidel, San Diego, CA). C3bBbP, the properdin-containing AP convertase reflecting AP activation, was quantified as previously described (139). Values for all activation products except $\mathrm{C} 4 \mathrm{~d}$ are given in arbitrary units (AU) defined by serum standards activated with heat aggregated $\operatorname{IgG}$ and zymosan and defined to contain $1000 \mathrm{AU} / \mathrm{mL}$. C4d are given in $\mu \mathrm{g} / \mathrm{mL}$ according to a standard delivered by the kit. 


\subsubsection{Wielisa}

Platelets are coated with IgM for measurement of CP activation, mannan for measurement of LP activation, and lipopolysaccharide from Salmonella typhi for measurement of AP activation (149;150). Serum is diluted in specific buffers according to the activating pathway. For $\mathrm{CP}$ activation, human serum is diluted 1:101 in a veronal buffer containing both free calcium and magnesium. For LP-activation, human serum is diluted 1:101 in a veronal buffer containing free calcium and magnesium and monoclonal anti-C1q antibodies to prevent $\mathrm{CP}$ activation. For AP activation, human serum is diluted 1:18 in a Mg-EGTA buffer with free magnesium and no calcium. Serum is then incubated for one hour at $37^{\circ} \mathrm{C}$. After washing, alkaline phosphatease-conjugated antihuman C5b-9 (clone aE11) is added before a new incubation for 30 minutes. The monoclonal antibody aE11 reacts with a neoepitope exposed in $\mathrm{C} 9$ after incorporation in the $\mathrm{C} 5 \mathrm{~b}-9$ complex. aE1 1 cross-reacts with specific pig epitopes (151).

\subsubsection{Multiplex}

Multiplex arrays are developed from traditional ELISAs to measure multiple mediators at the same time (145). They are based on the utilization of flowcytometry, chemiluminiscence or electrochemiluminiscence technology. The Luminex multianalyte profiling technology employ proprietary bead sets which are distinguishable under flowcytometry. Each bead set is coated with a specific capture antibody and fluorescence or streptavidin-labeled antibodies bind to the specific cytokine capture antibody complex on the bead set. The following cytokines, chemokines and growth factors were measured on a Bioplex Array Reader (LUMINEX 100, Bio-Rad Laboratories, Hercules, CA) using Bio-Plex Human Cytokine 27-plex panel (Bio-Rad Laboratories, Hercules, CA): IL-1Ra, IL-1 $\beta$, IL-2, IL-4, IL-5, IL-6, IL-7, IL-8, IL-9, IL-10, IL-12p70, IL-13, IL-15, IL-17, TNF- $\alpha$, IFN$\gamma$, MIP-1 $\alpha$, MIP-1 $\beta$, eotaxin, MCP-1, G-CSF, GM-CSF, basic FGF, VEGF, IP-10, RANTES, and PDGFbb. 


\subsection{In vivo}

\subsubsection{The animal model}

The anatomy and physiology of newborn pigs as well as body weight are comparable to human newborns (152). Pigs are not genetically identical as rodents. Newborn Noroc (LYxLD) pigs (crossbred between Norwegian Landrace (L) 1/2, Yorkshire (Y) $1 / 4$ and Duroc (D) $1 / 4$ ), 12-36 hours old, were delivered by a local farmer on the day of the experiment.

\subsubsection{Animal Preparation, Anaesthesia and Surgery}

Most anaesthetics have cardiodepressive effects. All animals received the same drugs indicating that these effects would influence the control group as well as the interventional group.

In paper I, anaesthesia was induced by halothane $4 \%$ in an equal mixture of air and oxygen $(3 L+3 L)$ until sleep, maintenance level of halothane was $1-2 \%$. In paper IV, anaesthesia was induced by sevofluran $7 \%$, reduced to a maintenance level of $2 \%$. An ear vein was cannulated. The pigs were tracheotomised using local infiltration anaesthesia (lidocain 10mg/mL, maximum $7 \mathrm{mg} / \mathrm{kg}$ ) and ventilated through an uncuffed endotracheal tube, inner diameter $3.5 \mathrm{~mm}$ (Portex Ltd., Hythe, Kent, UK) by a Babylog 8000 plus ventilator (Dräger Medical AG, Lübeck, Germany), shortly interrupted by manual ventilation (Laerdal silicon resuscitation bag, infant size; Laerdal, Stavanger, Norway). After tracheotomy intravenous anaesthesia replaced halothane/sevoflurane by boluses of pentobarbital sodium $(20 \mathrm{mg} / \mathrm{kg})$ and fentanyl $(12-20 \mu \mathrm{g} / \mathrm{kg}$ ) and maintained by infusion of fentanyl $25-50 \mu \mathrm{g} / \mathrm{kg} / \mathrm{h}$ and midazolam $250 \mu \mathrm{g} / \mathrm{kg} / \mathrm{h}$. A continuous intravenous infusion containing $0.7 \% \mathrm{NaCl}$ and $1.25 \%$ glucose at $6 \mathrm{~mL} / \mathrm{kg} / \mathrm{h}$ was given through polythene catheters (Portex PE-50, ID 0,96mm, Portex Ltd., Hythe, Kent UK) by syringe pumps (IVAC P 2000, Basingstoke, UK, and THERUMO STC-521, Tokyo, Japan). 
Halothane depresses cardiovascular function, but these effects are time and dose dependant. Halothane may cause malignant hyperthermia and tetanus in older pigs (153). Sevoflurane induces anaesthesia faster than halothane. It may also have cardiodepressive effects, but it is used in pigs and other animals both in research and in veterinary medicin $(154 ; 155)$. The barbiturate Pentobarbital was used for induction and the final overdose. Pentobarbital have cardio-depressive effects which are dosedependent, but are generally well tolerated in pigs (156).

Fentanyl and midazolam were used for analgesia and sedation. Pigs may need relatively large doses of opioids for analgesia $(157 ; 158)$. Midazolam is an effective sedative in pigs with minimal cardiovascular effects (159).

Volume resuscitation with $10-20 \mathrm{~mL} \mathrm{NaCl} 9 \mathrm{mg} / \mathrm{mL}$ up to three times during the experiment was given if needed. Central venous access was via the external jugular vein. Mean arterial blood pressure was recorded by a polythene catheter placed in the femoral artery. By means of pressure transducers (Edwards Life Science, Hina, Dominican Republic), hemodynamic data were collected in a computer system (Model MP 100, Biopac systems Inc., Santa Barbara, CA). Initial ventilator setting was peak inspiratory pressure (PIP) $18-20 \mathrm{~cm} \mathrm{H}_{2} \mathrm{O}$, ventilator rate $30 / \mathrm{min}$, positive end expiratory pressure PEEP) $4 \mathrm{~cm} \mathrm{H}_{2} \mathrm{O}$, inspiratory time $0.4 \mathrm{~s}$, and fraction of inspired oxygen $\left(\mathrm{FiO}_{2}\right)$ 0.21. During the experiment, PIP could if needed be increased to maximum $45 \mathrm{~cm} \mathrm{H}_{2} \mathrm{O}$ and the ventilator rate until maximum $60 /$ min to keep tidal volume at $8-14 \mathrm{~mL} / \mathrm{kg}$, arterial oxygen saturation at $\geq 90 \%$ and $\mathrm{PaCO}_{2}$ at $4-7 \mathrm{kPa}$. End-tidal $\mathrm{CO}_{2}$ was continuously monitored (Datex Normocap Oxy, Datex, Helsinki, Finland). Rectal temperature was kept between 38.5 and $39.5{ }^{\circ} \mathrm{C}$ with a heating lamp or a heating blanket. At the end of the experiment the pigs were killed with a bolusinjection of pentobarbital sodium.

\subsection{Data presentation and Statistics}

\section{Paper I}

Data are given as medians with interquartile ranges. Nonparametric tests were used for statistical analysis. Wilcoxon signed rank test was used for in-group differences, Mann-Whitney Wilcoxon test when comparing two groups, and Kruskal-Wallis test 
when comparing three groups. A two-tailed p-value below 0.05 was considered significant.

\section{Paper II}

Groups in figure 1 were compared using Mann-Whitney U Test in PRISM (Graph Pad Software Inc, San Diego, CA). The data are presented as medians with interquartile ranges. A two-tailed p-value below 0.05 was considered significant.

Groups in figures 2-5 were compared in a two-way repeated measurements analysis of variance (ANOVA) in PRISM (Graph Pad Software Inc, San Diego, CA) to explore the effect of dose and treatment. The data are presented as mean values with $95 \%$ confidence intervals. A two-tailed p-value below 0.05 was considered significant.

\section{Paper III}

Data are given as medians and interquartile ranges of 6 different experiments for all parameters except for IL-8 and LPS, where data are give in medians and ranges of three experiments. Due to the large numbers of readouts and experiments with different inhibitors and their combinations, statistical calculation was limited to the primary study aim, namely to compare the meconium-induced increase of a mediator with the effect of the combined inhibition with complement and anti-CD14. Nonparametric Wilcoxon's test was used for experiments with 6 observations and Student-t test with three. A two-tailed p-value below 0.05 was considered significant.

\section{Paper IV}

Data from the titration of CyP and meconium $(n=2)$ are presented as means with ranges. Data from the inhibition with $\mathrm{CyP}$ and anti-CD14 are presented as means with 95\% confidence interval. Data from the inhibition experiment are compared using repeated measurements ANOVA with Tukey as a post test. A two-tailed $p$ value below 0.05 was considered significant.

\section{Paper V}

Data are presented as medians of absorbance values (Figure 1) and standardized to values using NHS diluted 1/101 (set at 100\%) with range in Figure 2, 3 and 5 and in a frequency distribution histogram for Figure 4. 


\section{MAIN RESULTS}

\section{Paper I}

\section{Albumin lavage does not improve the outcome of meconium aspiration syndrome}

In this study of experimental meconium aspiration syndrome in newborn pigs we found that albumin lavage did not improve the outcome, rather the opposite. OI, VI, $\mathrm{FiO}_{2}$, and TCC increased significantly and compliance decreased significantly in the meconium-albumin group compared to the meconium group. There were no significant differences in release of proinflammatory cytokines between the two groups.

\section{Paper II}

\section{Mechanisms of complement activation and the effects of $\mathrm{C} 1$-inhibitor on the meconium-induced inflammatory reaction in cord blood}

This study demonstrated for the first time a role for the lectin pathway in meconiuminduced complement activation. Meconium activated the lectin complement pathway as well as the alternative complement pathway.

We also found a substantial inhibitory effect of C1-INH in supraphysiological concentrations in cord blood, attenuating the meconium-induced release of a broad panel of cytokines, chemokines and growth factors. In fact, all mediators induced by meconium measured in this study were inhibited considerably by C1-INH.

\section{Paper III}

\section{Role of complement and CD14 in meconium-induced cytokine formation}

In this study we demonstrated for the first time that meconium induced a potent CD14-mediated inflammatory reaction reflected by synthesis of a broad panel of 
cytokines, chemokines and growth factors in adult and cord human whole blood. Inhibition of CD14 markedly reduced the production of a number of the inflammatory mediators; complement inhibition reduced some of the mediators to a certain extent, whereas the combined inhibition of CD14 and complement had a remarkable effect on virtually all of the mediators studied. This combined effect was more pronounced than could be predicted from the effect of separate inhibition of CD14 and complement. Thus, these data indicate a synergistic effect of blocking these two main branches of innate immunity on the inflammatory response induced by meconium. The meconium-induced cytokine formation was generally more potent in cord blood than in adult blood. In general, cord blood seemed to be more sensitive to meconiuminduced activation than adult blood and the effect of inhibition of CD14 and complement was also more efficient in cord blood.

The LPS content of meconium used in this study was low. Adding LPS in increasing concentration to meconium did not increase the meconium-induced cytokine formation further, indicating that the CD14-mediated inflammatory response must be caused by other factors than LPS, probably endogenous substances.

\section{Paper IV}

\section{Meconium-induced release of cytokines is mediated by the TLR4- MD2 complex in a CD14-dependant manner}

In this study we demonstrated that meconium-induced cytokine, chemokine and growth factor formation mainly is mediated through the TLR4/MD-2 complex as shown by a substantial inhibition of biomarker release using the LPS antagonist CyP. We further demonstrated the necessity of CD14 in meconium-induced activation of the TLR4/MD-2 complex. Experiments using cells transfected with TLR2/TLR4, MD-2, and/or CD14, using TLR9 as control, confirmed these data. Thus the previously observed dependency of meconium-induced cytokine formation can be attributed to signalling via the CD14/TLR4/MD-2 complex. Finally the TLR4/MD-2 complex seemed to be involved in meconium-induced inflammation by endogenous mechanisms. 


\section{Paper V}

\section{Pathway-specific complement activity in pigs evaluated with a human}

\section{functional complement assay}

This paper demonstrated for the first time that normal pig serum has a fully active CP, LP, and AP detected in a human assay for total complement activity. LP activity was consistent with a distribution of MBL-deficiencies similar to that found in humans.

Finally, the assay can be used to evaluate and monitor complement inhibition both in vitro and in vivo. 


\section{DISCUSSION}

\subsection{Etiological consideration}

Despite a declining incidence of severe MAS in the developed world, MAS is still a major cause of respiratory distress in term and post term infants especially in the developing world $(5 ; 160)$. Extensive research on prevention and intervention has been performed. Still only supportive treatment is generally used and the only intervention that probably has declined the incidence is delivery at term. The pathophysiology is still poorly understood, especially the prenatal events leading to meconium aspiration and the fact that some children may aspirate meconium without the development of severe symptoms or complications.

\subsection{Albumin and the animal model}

In our first paper we used an experimental model of meconium aspiration syndrome in newborn pigs. Several animal and also a few human studies using surfactant in MAS have been performed. Repeated bolus doses of surfactant probably reduced the need for ECMO in ventilated children suffering from MAS $(65 ; 66)$. Therapeutic lung lavage using surfactant has been performed in several animal models, but few randomized controlled studies are published. A Cochrane review concludes that surfactant administration may reduce the severity of respiratory illness and decrease the number of infants with progressive respiratory failure requiring ECMO (69). Tølløfsrud compared the instillation of meconium alone with meconium mixed with albumin in newborn pigs and found significantly reduced oxygenation index, ventilation index and increased dynamic compliance (137). We instilled albumin 5 min after instillation of meconium to lavage the lungs. Albumin was meant to bind and neutralize detrimental components of meconium, and the lavage should help clean the airways. Albumin lavage had no effect on MAS, rather the opposite (paper I). We also found that this animal model was far from optimal. Some of the pigs got very sick while others did very well. The fact that prenatal events contribute considerably to severe MAS $(12 ; 161)$ makes it difficult to find an optimal animal model. 


\subsection{Complement activation}

In paper II we confirmed earlier findings that meconium is a potent activator of the complement system (49) through the alternative complement pathway. As the alternative pathway acts as an amplification loop of all initial pathways $(101 ; 104)$ we studied a possible role for the lectin pathway as an initial activation mechanism in meconium-induced complement activation. The fact that the inhibitory anti-MBL antibody $3 \mathrm{~F} 8$, reduced meconium-induced $\mathrm{C} 4 \mathrm{~d}$ formation suggests that meconium activates the lectin pathway directly (paper II). Meconium-induced formation of TCC was less reduced than $\mathrm{C} 4 \mathrm{~d}$, indicating that the alternative pathway seems to be activated directly by meconium as well as being amplified after the initial lectin pathway activation. This is in accordance with recent view that the alternative pathway both act as an initial recognition system via properdin, as well as amplifying the other initial pathways (97).

\subsection{C1-inhibitor}

In paper II we investigated the effect of the serine protease $\mathrm{C} 1-\mathrm{INH}$ on meconiuminduced inflammation in cord whole blood. We demonstrated for the first time a substantial inhibitory effect of $\mathrm{C} 1-\mathrm{INH}$, reducing meconium-induced formation of cytokines, chemokines and growth factors by an average of 60-70\%. C1-INH controls the classical pathway proteases $\mathrm{C} 1 \mathrm{r}$ and $\mathrm{C} 1 \mathrm{~s}$ (112), and also regulates lectin pathway by inhibiting its main protease MASP-2 (113). This may explain why C1-INH reduced $\mathrm{C} 4 \mathrm{~d}$ formation in our study. The inhibitory effect of $\mathrm{C} 1-\mathrm{INH}$ on the alternative pathway activation product, $\mathrm{C} 3 \mathrm{bBbP}$, can be explained both by a combined effect of less activation of the lectin pathway and thereby less triggering of the amplification loop, and also by a protease independent interaction between $\mathrm{C} 1$-INH and $\mathrm{C} 3 \mathrm{~b}$, preventing the binding of factor B (114).

MAS is associated with an inflammatory response $(50 ; 53 ; 53)$ and the fact that $\mathrm{C} 1$ INH in supraphysiological conditions substantially inhibited meconium-induced formation of all inflammatory mediators induced by meconium, makes it interesting to consider $\mathrm{C} 1-\mathrm{INH}$ infusion to be an alternative approach to reduce the inflammatory response in MAS. 


\subsection{Complement, TLRs and LPS}

The complement system and the CD14/TLR4/MD-2 complex are two main branches of innate immunity. In paper III we demonstrated that the meconium- induced inflammatory response is mediated through the main branches of the innate immune system, the CD14/TLR4/MD-2 complex and complement in human whole blood and cord blood. We demonstrated for the first time that meconium induced a potent CD14-mediated inflammatory reaction reflected by synthesis of a broad panel of cytokines, chemokines and growth factors in both human adult and cord whole blood. Inhibition of CD14 markedly reduced the formation of many mediators, inhibition of complement reduced some of the mediators, but the combined effect of inhibiting both systems had a remarkable effect on almost all mediators induced by meconium. The combined effect was more pronounced than could be predicted by separate inhibition alone, indicating a synergistic effect. This effect has not been described for meconium earlier. Brekke et al. found that the combined inhibition of both complement and CD14 in human whole blood blocked E.coli-induced granulocyte and monocyte up-regulation of CD11b, abolished oxidative burst and reduced phagocytosis (162). The combined inhibition also inhibited E.coli-induced inflammatory respone in human whole blood measured by several inflammatory mediators (163) as shown in our study.

The role of the TLR4/MD-2 complex was further investigated in paper IV, comparing the effect of MD-2 inhibition by CyP with CD14 inhibition, and the investigation of CD14, MD-2 and TLR4 in human transfected cell lines. We demonstrated for the first time that meconium-induced cytokine, chemokine and growth factor formation mainly is mediated through the TLR4/MD-2 complex as shown by a substantial inhibition of biomarker-release using the LPS-antagonist CyP. Furthermore, we documented the requirement of CD14 for this response using transfected cells. The specificity of TLR4 was also shown in the transfected cells by including TLR2 and TLR9 transfectants. Thus, the previously observed CD14-dependency of meconiuminduced cytokine formation in paper III can be attributed to signaling via the CD14/TLR4/MD-2 complex. 
MD-2 is a necessary cofactor for TLR4 in the detection of LPS. This process is greatly enhanced by CD14 and LPS-binding protein (120;121) Soluble MD-2 binds LPS directly with high affinity and the LPS/MD-2 complex forms a ligand activating TLR4-positive cells (122). CyP binds the TLR4/MD-2 complex directly, competitively inhibiting binding to LPS (123). CyP protects mice from LPS-induced shock and exerts its inhibitory activity in dendritic cells by immediately downregulation of inflammatory cytokine mRNAs even if added hours after LPS. CyP is a potent antagonist of meningococcal LPS (124) and an efficient inhibitor of $E$. coli-LPS-induced cytokine release (125). In the present study CyP decreased meconium-induced formation of most mediators measured considerably and to virtually the same extent as anti-CD14, suggesting that the CD14-dependent effect of meconium-induced inflammation is mediated solely through the TLR4/MD-2 complex.

\subsection{LPS and endogenous activation of the inflammatory response}

Meconium and amniotic fluid have been considered to be sterile as well as the gastrointestinal tract of the normal fetus (29). However, several bacteria have been detected in meconium samples from healthy newborns (31), the prevalence of positive amniotic fluid cultures was significantly higher in women with MSAF and intact membranes than in women with clear fluid (20), and fetal membranes, even from deliveries by cesarean section at term, have microbial organisms present (30). Meconium may contain various amounts of proinflammatory substances including TNF- $\alpha$, IL-1 $\beta$, IL-6 and IL-8 (28). In vitro meconium is chemotactic to neutrophils (33) and possibly vasoactive (34). Toxic effects of meconium trigger inflammation in the lungs $(39 ; 47)$. Activated neutrophils and macrophages are detected in the lung parenchyma and alveoli only hours after meconium aspiration (48). The release of proinflammatory cytokines may directly injure the lung parenchyma resulting in vascular leakage causing pneumonitis and pulmonary edema (51;52). Meconiuminduced inflammatory lung injury is associated with respiratory epithelial apoptosis in several animal models $(52 ; 54)$. 
The cellular response of innate immunity is composed mainly of the TLR family with the CD14/TLR4/MD-2 complex as a main constituent. LPS is the main exogenous ligand for TLR4, but there are a number of endogenous candidates (e.g. heparan sulfate, hyaluronon, fibrinogen) (164). The LPS content in meconium used in paper III was as low as $20 \mathrm{pg} / \mathrm{mg}$ meconium. LPS contents in the range of $\mu \mathrm{g} / \mathrm{mL}$ is needed to induce complement activation $(162 ; 165)$. Thus, the complement activation potency of meconium is not related to LPS, although a potential for LPS to induce cytokine production can not be fully excluded. If there should be a contribution from LPS in the meconium-induced cytokine formation, $\mathrm{C} 1-\mathrm{INH}$ is in fact a candidate for neutralizing this effect in a complement-independent manner. Zhang et al demonstrated that a peptide from the amino-terminal end of C1-INH neutralizes LPS either by direct binding to LPS or competing with its receptor on CD14 (166). Contamination of meconium by bacterial products including LPS should be carefully considered. In paper V, the LPS content of the meconium was $30 \mathrm{EU} / \mathrm{mg}$ meconium (or $3 \mathrm{ng} / \mathrm{mg}$ meconium). In paper III we investigated the role of LPS in meconiuminduced cytokine formation by comparing meconium-induced and LPS-induced cytokine formation in human blood. The cytokine formation induced by meconium containing $20 \mathrm{pg} \mathrm{LPS} / \mathrm{mg}$, at $1 \mathrm{mg}$ meconium $/ \mathrm{mL}$ whole blood, was considerably higher than that induced by LPS at concentration up to $10 \mathrm{ng} / \mathrm{mL}$ blood. In paper IV we found a higher LPS content of meconium than in the paper III, most likely reflecting the different LPS-assays used. We therefore again compared LPS and meconium-induced proinflammatory cytokine formation in "LPS-equivalent" doses and found a dose-dependent increased formation of TNF $\alpha$, IL-1 $\beta$, IL- 6 and IL- 8 with increasing concentrations of meconium and LPS. Meconium-induced cytokine formation was 5-15 folds higher compared to the increase seen with equivalent doses of LPS. The relative difference increased with increasing concentrations of meconium. We therefore conclude that LPS, although contributing to a certain extent, could not explain the meconium-induced inflammatory reaction. Meconium contains innumerable agents which are candidates for endogenous danger signaling, in particular since it contains "damaged self". Cell-surface TLRs are known to respond to many endogenous ligands like heparan sulfate, hyaluronan, fibrinogen, surfactant protein A, fibronectin, HMGB1 and $\beta$-defensin $(164 ; 167)$. We therefore suggest that the inflammatory response induced by meconium, mainly is mediated by endogenous ligands, although the candidate substances are currently unknown. It was out of scope 
of the present study to search for candidate substances, but it will be important to continue this research in order to identify actual ligands.

\subsection{Cord blood versus adult blood}

As MAS is a disease of the newborn, the study in paper II was performed in cord blood. The study in paper III was performed in both adult and cord human whole blood, the latter to emphasize the relevance of the disease and the former to pinpoint the difference between immature and mature immunity. We found that meconiuminduced cytokine formation was generally more potent in cord blood than in adult blood. The effect of inhibition of meconium-induced cytokine formation by inhibiting either complement or CD14 was more efficient in cord blood compared to adult blood, but the combined inhibition of both systems almost completely abolished the formation of proinflammatory cytokines and chemokines in both adult and cord blood. In contrast, in a study performed by Bessler et al, using cells isolated from cord blood, there were fewer CD14-positive mononuclear cells and a lower CD14 content on each cell compared to adult blood (168). According to Levy, neonatal monocytes express normal basal levels of membrane CD14 and TLR4, but levels of CD14 may be low in prematures $(133 ; 134)$. After stimulation with LPS, neonatal neutrophils and monocytes demonstrate reduced expression of CD14 than adult cells.

Cord blood is known to contain approximately half the amount of complement components compared to adult blood $(135 ; 136)$. That is in accordance with our finding in newborn pigs in paper IV.

\subsection{Testing of porcine complement activity}

In for instance sepsis research, large animals as pigs are commonly used as research animals. They are seldom genetically identical as rodents, so their immunity status may differ. In paper $\mathrm{V}$, we demonstrated for the first time that normal pig serum has a fully active CP, LP, and AP detected in a human assay for measurement of total complement activity. LP activity was consistent with a distribution of MBLdeficiencies similar to that found in humans consistent with previous findings (169). 
Newborn pigs showed lower activity in all three complement activation pathways compared to older animals. The human Wielisa test may also be used in pigs after certain modifications (Paper V). Inhibition of pig complement in vitro and monitoring inhibition in vivo can successfully be studied. Thus, we assume that the human Wielisa test will be a useful tool for investigating complement activity in experimental pig models. Finally, the assay can be used to evaluate and monitor complement inhibition both in vitro and in vivo.

\subsection{Limitations}

The main limitation to our findings in paper II-IV is that these studies are in vitro studies. The incubation period was four hours. This is the period in which the physiological conditions in the blood are relatively stable. Other cell types are also present in the lung and participate in lung injury in vivo so our results should be interpreted with caution. However, most proinflammatory cytokines and chemokines induced by meconium in our studies were significantly elevated in sera from neonates with MAS as well as the anti-inflammatory cytokine IL-10 (53). The effect of complement inhibition, anti CD14 and CyP may be different in vivo.

\subsection{Clinical application}

Prenatal events are important. The pathophysiology of MAS needs further investigations, including the prenatal events. Some of our findings like the synergistic effect of inhibiting both complement and the CD14/TLR4/MD-2 complex and the ability of $\mathrm{C} 1-\mathrm{INH}$ concentrate to reduce the meconium-induced inflammatory response, may be potential mechanisms we can explore further with the intention to reduce the inflammatory reaction in MAS.

\subsection{Future perspectives}

Further investigations considering the pathophysiology of MAS are important especially the prenatal events, but also inflammatory aspects. Our present and future findings with the intention to reduce the inflammatory response of MAS need to be tested in vivo. Appropriate animal models must be thoroughly chosen. 
Meconium is an interesting substance in studies of inflammation. Especially the activation of TLR4 by endogenous mechanisms and probably also to an extent by exogenous mechanisms that are not described earlier. Investigating these mechanisms further would be important in order to develop a rational for causal treatment of the inflammatory aspects of MAS. 


\section{CONCLUSIONS}

1: Albumin lavage did not improve the outcome of experimental meconium aspiration syndrome in newborn pigs, rather the opposite as $\mathrm{OI}, \mathrm{VI}, \mathrm{FiO}_{2}$, significantly increased and dynamic compliance significantly decreased in the meconium-albumin group.

2: Meconium activated the lectin complement pathway as well as the alternative complement pathway. C1-INH in supraphysiological concentrations substantially inhibited meconium-induced inflammation in human whole blood.

3: Meconium induced a potent CD14-mediated inflammatory reaction reflected by synthesis of a broad panel of cytokines, chemokines, and growth factors in human adult and cord whole blood. The combined inhibition of both complement and CD14 showed a remarkable effect of almost all mediators induced by meconium, suggesting a synergistic effect of blocking these two main branches of innate immunity. The CD14 effect cannot be explained by the lipopolysaccharide content of meconium.

4: Meconium-induced cytokine, chemokine and growth factor formation is mediated through the TLR4/MD-2 complex as shown by a substantial inhibition of the biomarker release by using the LPS antagonist CyP. CD14 is required for this response. Meconium contains substances that may activate the TLR4/MD-2 complex mainly by endogenous mechanisms.

5: Normal pig serum has a fully active CP, LP, and AP detected in a human assay for total complement activity. LP activity was consistent with a distribution of MBLdeficiencies similar to that found in humans. The assay may also be used to evaluate and monitor complement inhibition both in vitro and in vivo.

\section{In general:}

Meconium-induced inflammation is mediated by complement and the CD14/TLR4/MD-2 complex. Pathophysiological mechanisms need further investigations, though our results using a combined inhibition of both these main 
branches of innate immunity must be an interesting approach to treat the inflammatory reaction in MAS. 


\section{REFERENCES}

(1) Cleary GM, Wiswell TE. Meconium-stained amniotic fluid and the meconium aspiration syndrome. An update. Pediatr Clin North Am 1998 Jun;45(3):51129.

(2) Greenough A. Meconium aspiration syndrome--prevention and treatment. Early Hum Dev 1995 Apr 28;41(3):183-92.

(3) Adhikari M, Gouws E. Meconium aspiration in South Africa. S Afr Med J 1995 Sep;85(9):891-3.

(4) Wiswell TE, Tuggle JM, Turner BS. Meconium aspiration syndrome: have we made a difference? Pediatrics 1990 May;85(5):715-21.

(5) Dargaville PA, Copnell B. The epidemiology of meconium aspiration syndrome: incidence, risk factors, therapies, and outcome. Pediatrics 2006 May;117(5):1712-21.

(6) Yoder BA, Kirsch EA, Barth WH, Gordon MC. Changing obstetric practices associated with decreasing incidence of meconium aspiration syndrome. Obstet Gynecol 2002 May;99(5 Pt 1):731-9.

(7) Gregory GA, Gooding CA, Phibbs RH, Tooley WH. Meconium aspiration in infants--a prospective study. J Pediatr 1974 Dec;85(6):848-52.

(8) Davis RO, Philips JB, III, Harris BA, Jr., Wilson ER, Huddleston JF. Fatal meconium aspiration syndrome occurring despite airway management considered appropriate. Am J Obstet Gynecol 1985 Mar 15;151(6):731-6.

(9) Falciglia HS, Henderschott C, Potter P, Helmchen R. Does DeLee suction at the perineum prevent meconium aspiration syndrome? Am J Obstet Gynecol 1992 Nov;167(5):1243-9.

(10) Whitfield JM, Charsha DS, Chiruvolu A. Prevention of meconium aspiration syndrome: an update and the Baylor experience. Proc (Bayl Univ Med Cent ) 2009 Apr;22(2):128-31.

(11) Blackwell SC, Moldenhauer J, Hassan SS, Redman ME, Refuerzo JS, Berry $\mathrm{SM}$, et al. Meconium aspiration syndrome in term neonates with normal acidbase status at delivery: is it different? Am J Obstet Gynecol 2001 Jun;184(7):1422-5.

(12) Ghidini A, Spong CY. Severe meconium aspiration syndrome is not caused by aspiration of meconium. Am J Obstet Gynecol 2001 Oct;185(4):931-8. 
(13) Thureen PJ, Hall DM, Hoffenberg A, Tyson RW. Fatal meconium aspiration in spite of appropriate perinatal airway management: pulmonary and placental evidence of prenatal disease. Am J Obstet Gynecol 1997 May;176(5):967-75.

(14) Wiswell TE, Gannon CM, Jacob J, Goldsmith L, Szyld E, Weiss K, et al. Delivery room management of the apparently vigorous meconium-stained neonate: results of the multicenter, international collaborative trial. Pediatrics 2000 Jan;105(1 Pt 1):1-7.

(15) Vain NE, Szyld EG, Prudent LM, Wiswell TE, Aguilar AM, Vivas NI. Oropharyngeal and nasopharyngeal suctioning of meconium-stained neonates before delivery of their shoulders: multicentre, randomised controlled trial. Lancet 2004 Aug 14;364(9434):597-602.

(16) Matthews TG, Warshaw JB. Relevance of the gestational age distribution of meconium passage in utero. Pediatrics 1979 Jul;64(1):30-1.

(17) Usher RH, Boyd ME, McLean FH, Kramer MS. Assessment of fetal risk in postdate pregnancies. Am J Obstet Gynecol 1988 Feb;158(2):259-64.

(18) Lucas A, Adrian TE, Christofides N, Bloom SR, ynsley-Green A. Plasma motilin, gastrin, and enteroglucagon and feeding in the human newborn. Arch Dis Child 1980 Sep;55(9):673-7.

(19) Hernandez C, Little BB, Dax JS, Gilstrap LC, III, Rosenfeld CR. Prediction of the severity of meconium aspiration syndrome. Am J Obstet Gynecol 1993 Jul;169(1):61-70.

(20) Romero R, Espinoza J, Goncalves LF, Kusanovic JP, Friel LA, Nien JK. Inflammation in preterm and term labour and delivery. Semin Fetal Neonatal Med 2006 Oct;11(5):317-26.

(21) Coughtrey H, Jeffery HE, Henderson-Smart DJ, Storey B, Poulos V. Possible causes linking asphyxia, thick meconium and respiratory distress. Aust N Z J Obstet Gynaecol 1991 May;31(2):97-102.

(22) Ahanya SN, Lakshmanan J, Morgan BL, Ross MG. Meconium passage in utero: mechanisms, consequences, and management. Obstet Gynecol Surv 2005 Jan;60(1):45-56.

(23) Clausson B, Cnattingius S, Axelsson O. Outcomes of post-term births: the role of fetal growth restriction and malformations. Obstet Gynecol 1999 Nov;94(5 Pt 1):758-62.

(24) Perlman EJ, Moore GW, Hutchins GM. The pulmonary vasculature in meconium aspiration. Hum Pathol 1989 Jul;20(7):701-6.

(25) RAPOPORT S, BUCHANAN DJ. The composition of Meconium; isolation of blood-group-specific polysaccharides; abnormal compositions of meconium in meconium ileus. Science 1950 Aug 4;112(2901):150-3. 
(26) Wiswell TE, Bent RC. Meconium staining and the meconium aspiration syndrome. Unresolved issues. Pediatr Clin North Am 1993 Oct;40(5):955-81.

(27) Antonowicz I, Shwachman H. Meconium in health and in disease. Adv Pediatr 1979;26:275-310.

(28) de Beaufort AJ, Bakker AC, van Tol MJ, Poorthuis BJ, Schrama AJ, Berger HM. Meconium is a source of pro-inflammatory substances and can induce cytokine production in cultured A549 epithelial cells. Pediatr Res 2003 Oct;54(4):491-5.

(29) Mackie RI, Sghir A, Gaskins HR. Developmental microbial ecology of the neonatal gastrointestinal tract. Am J Clin Nutr 1999 May;69(5):1035S-45S.

(30) Steel JH, Malatos S, Kennea N, Edwards AD, Miles L, Duggan P, et al. Bacteria and inflammatory cells in fetal membranes do not always cause preterm labor. Pediatr Res 2005 Mar;57(3):404-11.

(31) Jimenez E, Marin ML, Martin R, Odriozola JM, Olivares M, Xaus J, et al. Is meconium from healthy newborns actually sterile? Res Microbiol 2008 Jan 11.

(32) Rubin BK, Tomkiewicz RP, Patrinos ME, Easa D. The surface and transport properties of meconium and reconstituted meconium solutions. Pediatr Res 1996 Dec;40(6):834-8.

(33) de Beaufort AJ, Pelikan DM, Elferink JG, Berger HM. Effect of interleukin 8 in meconium on in-vitro neutrophil chemotaxis. Lancet $1998 \mathrm{Jul}$ $11 ; 352(9122): 102-5$.

(34) Holopainen R, Soukka H, Halkola L, Kaapa P. Meconium aspiration induces a concentration-dependent pulmonary hypertensive response in newborn piglets. Pediatr Pulmonol 1998 Feb;25(2):107-13.

(35) Tyler DC, Murphy J, Cheney FW. Mechanical and chemical damage to lung tissue caused by meconium aspiration. Pediatrics 1978 Oct;62(4):454-9.

(36) Fuloria M, Wiswell TE. Resuscitation of the meconium-stained infant and prevention of meconium aspiration syndrome. J Perinatol 1999 Apr;19(3):23441.

(37) Yeh TF, Lilien LD, Barathi A, Pildes RS. Lung volume, dynamic lung compliance, and blood gases during the first 3 days of postnatal life in infants with meconium aspiration syndrome. Crit Care Med 1982 Sep;10(9):588-92.

(38) bu-Osba YK. Treatment of persistent pulmonary hypertension of the newborn: update. Arch Dis Child 1991 Jan;66(1 Spec No):74-7.

(39) Gelfand SL, Fanaroff JM, Walsh MC. Controversies in the treatment of meconium aspiration syndrome. Clin Perinatol 2004 Sep;31(3):445-52. 
(40) Soukka H, Jalonen J, Kero P, Kaapa P. Endothelin-1, atrial natriuretic peptide and pathophysiology of pulmonary hypertension in porcine meconium aspiration. Acta Paediatr 1998 Apr;87(4):424-8.

(41) Soukka H, Viinikka L, Kaapa P. Involvement of thromboxane A2 and prostacyclin in the early pulmonary hypertension after porcine meconium aspiration. Pediatr Res 1998 Dec;44(6):838-42.

(42) Soukka HR, Ahotupa M, Ruutu M, Kaapa PO. Meconium stimulates neutrophil oxidative burst. Am J Perinatol 2002 Jul;19(5):279-84.

(43) Kaapa P. Meconium aspiration syndrome: a role for phospholipase A2 in the pathogenesis? Acta Paediatr 2001 Apr;90(4):365-7.

(44) Clark DA, Nieman GF, Thompson JE, Paskanik AM, Rokhar JE, Bredenberg CE. Surfactant displacement by meconium free fatty acids: an alternative explanation for atelectasis in meconium aspiration syndrome. J Pediatr 1987 May;110(5):765-70.

(45) Dargaville PA, South M, McDougall PN. Surfactant and surfactant inhibitors in meconium aspiration syndrome. J Pediatr 2001 Jan;138(1):113-5.

(46) Moses D, Holm BA, Spitale P, Liu MY, Enhorning G. Inhibition of pulmonary surfactant function by meconium. Am J Obstet Gynecol 1991 Feb;164(2):477-81.

(47) Wiswell TE. Advances in the treatment of the meconium aspiration syndrome. Acta Paediatr Suppl 2001 Mar;90(436):28-30.

(48) Davey AM, Becker JD, Davis JM. Meconium aspiration syndrome: physiological and inflammatory changes in a newborn piglet model. Pediatr Pulmonol 1993 Aug;16(2):101-8.

(49) Castellheim A, Lindenskov PH, Pharo A, Fung M, Saugstad OD, Mollnes TE. Meconium is a potent activator of complement in human serum and in piglets. Pediatr Res 2004 Feb;55(2):310-8.

(50) Lindenskov PH, Castellheim A, Aamodt G, Saugstad OD, Mollnes TE. Complement activation reflects severity of meconium aspiration syndrome in newborn pigs. Pediatr Res 2004 Nov;56(5):810-7.

(51) Zagariya A, Bhat R, Navale S, Vidyasagar D. Cytokine expression in meconium-induced lungs. Indian J Pediatr 2004 Mar;71(3):195-201.

(52) Zagariya A, Bhat R, Uhal B, Navale S, Freidine M, Vidyasagar D. Cell death and lung cell histology in meconium aspirated newborn rabbit lung. Eur $\mathrm{J}$ Pediatr 2000 Nov;159(11):819-26.

(53) Okazaki K, Kondo M, Kato M, Kakinuma R, Nishida A, Noda M, et al. Serum cytokine and chemokine profiles in neonates with meconium aspiration syndrome. Pediatrics 2008 Apr;121(4):e748-e753. 
(54) Lukkarinen H, Laine J, Lehtonen J, Zagariya A, Vidyasagar D, Aho H, et al. Angiotensin II receptor blockade inhibits pneumocyte apoptosis in experimental meconium aspiration. Pediatr Res 2004 Feb;55(2):326-33.

(55) Rosenfeld CR, Zagariya AM, Liu XT, Willis BC, Fluharty S, Vidyasagar D. Meconium increases type 1 angiotensin II receptor expression and alveolar cell death. Pediatr Res 2008 Mar;63(3):251-6.

(56) Alexander GR, Hulsey TC, Robillard PY, De CF, Papiernik E. Determinants of meconium-stained amniotic fluid in term pregnancies. J Perinatol 1994 Jul;14(4):259-63.

(57) Sriram S, Wall SN, Khoshnood B, Singh JK, Hsieh HL, Lee KS. Racial disparity in meconium-stained amniotic fluid and meconium aspiration syndrome in the United States, 1989-2000. Obstet Gynecol 2003 Dec;102(6):1262-8.

(58) Urbaniak KJ, McCowan LM, Townend KM. Risk factors for meconiumaspiration syndrome. Aust N Z J Obstet Gynaecol 1996 Nov;36(4):401-6.

(59) Wiswell TE. Handling the meconium-stained infant. Semin Neonatol 2001 Jun;6(3):225-31.

(60) Xu H, Hofmeyr J, Roy C, Fraser WD. Intrapartum amnioinfusion for meconium-stained amniotic fluid: a systematic review of randomised controlled trials. BJOG 2007 Apr;114(4):383-90.

(61) Carson BS, Losey RW, Bowes WA, Jr., Simmons MA. Combined obstetric and pediatric approach to prevent meconium aspiration syndrome. Am J Obstet Gynecol 1976 Nov 15;126(6):712-5.

(62) Halliday HL. Endotracheal intubation at birth for preventing morbidity and mortality in vigorous, meconium-stained infants born at term. Cochrane Database Syst Rev 2001;(1):CD000500.

(63) Calkovska A, Sun B, Curstedt T, Renheim G, Robertson B. Combined effects of high-frequency ventilation and surfactant treatment in experimental meconium aspiration syndrome. Acta Anaesthesiol Scand 1999 Feb;43(2):135-45.

(64) Carter JM, Gerstmann DR, Clark RH, Snyder G, Cornish JD, Null DM, Jr., et al. High-frequency oscillatory ventilation and extracorporeal membrane oxygenation for the treatment of acute neonatal respiratory failure. Pediatrics 1990 Feb;85(2):159-64.

(65) Findlay RD, Taeusch HW, Walther FJ. Surfactant replacement therapy for meconium aspiration syndrome. Pediatrics 1996 Jan;97(1):48-52.

(66) Lotze A, Mitchell BR, Bulas DI, Zola EM, Shalwitz RA, Gunkel JH. Multicenter study of surfactant (beractant) use in the treatment of term infants with severe respiratory failure. Survanta in Term Infants Study Group. J Pediatr 1998 Jan;132(1):40-7. 
(67) Dargaville PA, Mills JF. Surfactant therapy for meconium aspiration syndrome: current status. Drugs 2005;65(18):2569-91.

(68) Wiswell TE, Knight GR, Finer NN, Donn SM, Desai H, Walsh WF, et al. A multicenter, randomized, controlled trial comparing Surfaxin (Lucinactant) lavage with standard care for treatment of meconium aspiration syndrome. Pediatrics 2002 Jun;109(6):1081-7.

(69) El SA, Dargaville P, Ohlsson A, Soll R. Surfactant for meconium aspiration syndrome in full term/near term infants. Cochrane Database Syst Rev 2007;(3):CD002054.

(70) Holopainen R, Laine J, Halkola L, Aho H, Kaapa P. Dexamethasone treatment attenuates pulmonary injury in piglet meconium aspiration. Pediatr Res 2001 Feb;49(2):162-8.

(71) Khan AM, Shabarek FM, Kutchback JW, Lally KP. Effects of dexamethasone on meconium aspiration syndrome in newborn piglets. Pediatr Res 1999 Aug;46(2):179-83.

(72) Ward M, Sinn J. Steroid therapy for meconium aspiration syndrome in newborn infants. Cochrane Database Syst Rev 2003;(4):CD003485.

(73) Salvia-Roiges MD, Carbonell-Estrany X, Figueras-Aloy J, RodriguezMiguelez JM. Efficacy of three treatment schedules in severe meconium aspiration syndrome. Acta Paediatr 2004 Jan;93(1):60-5.

(74) Tripathi S, Saili A, Dutta R. Inflammatory markers in meconium induced lung injury in neonates and effect of steroids on their levels: A randomized controlled trial. Indian J Med Microbiol 2007 Apr;25(2):103-7.

(75) Holopainen R, Soukka H, Halkola L, Kaapa P. Intravenous immunoglobulin g attenuates pulmonary hypertension but induces local neutrophil influx in meconium aspiration in piglets. Biol Neonate 2005;87(4):221-8.

(76) Zagariya A, Bhat R, Chari G, Uhal B, Navale S, Vidyasagar D. Apoptosis of airway epithelial cells in response to meconium. Life Sci 2005 Mar 4;76(16):1849-58.

(77) Zagariya A, Bhat R, Navale S, Chari G, Vidyasagar D. Inhibition of meconium-induced cytokine expression and cell apoptosis by pretreatment with captopril. Pediatrics 2006 May;117(5):1722-7.

(78) $\mathrm{Lu} \mathrm{KW}$, Goerke J, Clements JA, Taeusch HW. Hyaluronan reduces surfactant inhibition and improves rat lung function after meconium injury. Pediatr Res 2005 Aug;58(2):206-10.

(79) Angert RM, Pilon AL, Chester D, Davis JM. CC10 Reduces Inflammation in Meconium Aspiration Syndrome in Newborn Piglets. Pediatr Res 2007 Oct 12. 
(80) Medzhitov R, Janeway C, Jr. Innate immunity. N Engl J Med 2000 Aug 3;343(5):338-44.

(81) Seong SY, Matzinger P. Hydrophobicity: an ancient damage-associated molecular pattern that initiates innate immune responses. Nat Rev Immunol 2004 Jun;4(6):469-78.

(82) Janeway CA, Jr., Medzhitov R. Innate immune recognition. Annu Rev Immunol 2002;20:197-216.

(83) Matzinger P. Tolerance, danger, and the extended family. Annu Rev Immunol 1994;12:991-1045.

(84) Jeannin P, Jaillon S, Delneste Y. Pattern recognition receptors in the immune response against dying cells. Curr Opin Immunol 2008 Oct;20(5):530-7.

(85) Carroll MC. The complement system in regulation of adaptive immunity. Nat Immunol 2004 Oct;5(10):981-6.

(86) Epstein J, Eichbaum Q, Sheriff S, Ezekowitz RA. The collectins in innate immunity. Curr Opin Immunol 1996 Feb;8(1):29-35.

(87) Medzhitov R, Janeway C, Jr. The Toll receptor family and microbial recognition. Trends Microbiol 2000 Oct;8(10):452-6.

(88) Uthaisangsook S, Day NK, Bahna SL, Good RA, Haraguchi S. Innate immunity and its role against infections. Ann Allergy Asthma Immunol 2002 Mar;88(3):253-64.

(89) Mollnes TE, Christiansen D, Brekke OL, Espevik T. Hypothesis: combined inhibition of complement and CD14 as treatment regimen to attenuate the inflammatory response. Adv Exp Med Biol 2008;632:253-63.

(90) Zhang X, Kimura Y, Fang C, Zhou L, Sfyroera G, Lambris JD, et al. Regulation of Toll-like receptor-mediated inflammatory response by complement in vivo. Blood 2007 Jul 1;110(1):228-36.

(91) Hawlisch H, Kohl J. Complement and Toll-like receptors: key regulators of adaptive immune responses. Mol Immunol 2006 Jan;43(1-2):13-21.

(92) Kohl J. The role of complement in danger sensing and transmission. Immunol Res 2006;34(2):157-76.

(93) Medzhitov R. Origin and physiological roles of inflammation. Nature $2008 \mathrm{Jul}$ 24;454(7203):428-35.

(94) Barton GM. A calculated response: control of inflammation by the innate immune system. J Clin Invest 2008 Feb;118(2):413-20.

(95) Nathan C. Neutrophils and immunity: challenges and opportunities. Nat Rev Immunol 2006 Mar;6(3):173-82. 
(96) Walport MJ. Complement. First of two parts. N Engl J Med 2001 Apr 5;344(14):1058-66.

(97) Harboe M, Mollnes TE. The alternative complement pathway revisited. J Cell Mol Med 2008 Apr 15.

(98) Roos A, Bouwman LH, Munoz J, Zuiverloon T, Faber-Krol MC, Fallaux-van den Houten FC, et al. Functional characterization of the lectin pathway of complement in human serum. Mol Immunol 2003 Jan;39(11):655-68.

(99) Thiel S. Complement activating soluble pattern recognition molecules with collagen-like regions, mannan-binding lectin, ficolins and associated proteins. Mol Immunol 2007 Sep;44(16):3875-88.

(100) Mollnes TE, Song WC, Lambris JD. Complement in inflammatory tissue damage and disease. Trends Immunol 2002 Feb;23(2):61-4.

(101) Harboe M, Garred P, Borgen MS, Stahl GL, Roos A, Mollnes TE. Design of a complement mannose-binding lectin pathway-specific activation system applicable at low serum dilutions. Clin Exp Immunol 2006 Jun;144(3):512-20.

(102) Bexborn F, Andersson PO, Chen H, Nilsson B, Ekdahl KN. The tick-over theory revisited: formation and regulation of the soluble alternative complement C3 convertase (C3(H2O)Bb). Mol Immunol 2008 Apr;45(8):2370-9.

(103) Zipfel PF, Mihlan M, Skerka C. The alternative pathway of complement: a pattern recognition system. Adv Exp Med Biol 2007;598:80-92.

(104) Harboe M, Ulvund G, Vien L, Fung M, Mollnes TE. The quantitative role of alternative pathway amplification in classical pathway induced terminal complement activation. Clin Exp Immunol 2004 Dec;138(3):439-46.

(105) Haas PJ, van SJ. Anaphylatoxins: their role in bacterial infection and inflammation. Immunol Res 2007;37(3):161-75.

(106) Pasupuleti M, Walse B, Nordahl EA, Morgelin M, Malmsten M, Schmidtchen A. Preservation of antimicrobial properties of complement peptide $\mathrm{C} 3 \mathrm{a}$, from invertebrates to humans. J Biol Chem 2007 Jan 26;282(4):2520-8.

(107) Guo RF, Ward PA. Role of C5a in inflammatory responses. Annu Rev Immunol 2005;23:821-52.

(108) Kohl J. Anaphylatoxins and infectious and non-infectious inflammatory diseases. Mol Immunol 2001 Aug;38(2-3):175-87.

(109) Meri S. Loss of self-control in the complement system and innate autoreactivity. Ann N Y Acad Sci 2007 Aug;1109:93-105.

(110) Caliezi C, Wuillemin WA, Zeerleder S, Redondo M, Eisele B, Hack CE. C1Esterase inhibitor: an anti-inflammatory agent and its potential use in the 
treatment of diseases other than hereditary angioedema. Pharmacol Rev 2000 Mar;52(1):91-112.

(111) Davis AE, III. Biological effects of C1 inhibitor. Drug News Perspect 2004 Sep;17(7):439-46.

(112) Cooper NR. The classical complement pathway: activation and regulation of the first complement component. Adv Immunol 1985;37:151-216.

(113) Petersen SV, Thiel S, Jensen L, Vorup-Jensen T, Koch C, Jensenius JC. Control of the classical and the MBL pathway of complement activation. Mol Immunol 2000 Oct;37(14):803-11.

(114) Jiang H, Wagner E, Zhang H, Frank MM. Complement 1 inhibitor is a regulator of the alternative complement pathway. J Exp Med 2001 Dec 3;194(11):1609-16.

(115) Davis AE, III, Cai S, Liu D. C1 inhibitor: biologic activities that are independent of protease inhibition. Immunobiology 2007;212(4-5):313-23.

(116) Cicardi M, Zingale L, Zanichelli A, Pappalardo E, Cicardi B. C1 inhibitor: molecular and clinical aspects. Springer Semin Immunopathol 2005 Nov;27(3):286-98.

(117) Takeda K, Kaisho T, Akira S. Toll-like receptors. Annu Rev Immunol 2003;21:335-76.

(118) Shimazu R, Akashi S, Ogata H, Nagai Y, Fukudome K, Miyake K, et al. MD2, a molecule that confers lipopolysaccharide responsiveness on Toll-like receptor 4. J Exp Med 1999 Jun 7;189(11):1777-82.

(119) Daubeuf B, Mathison J, Spiller S, Hugues S, Herren S, Ferlin W, et al. TLR4/MD-2 monoclonal antibody therapy affords protection in experimental models of septic shock. J Immunol 2007 Nov 1;179(9):6107-14.

(120) Perera PY, Vogel SN, Detore GR, Haziot A, Goyert SM. CD14-dependent and CD14-independent signaling pathways in murine macrophages from normal and CD14 knockout mice stimulated with lipopolysaccharide or taxol. J Immunol 1997 May 1;158(9):4422-9.

(121) Nagai Y, Akashi S, Nagafuku M, Ogata M, Iwakura Y, Akira S, et al. Essential role of MD-2 in LPS responsiveness and TLR4 distribution. Nat Immunol $2002 \mathrm{Jul} ; 3(7): 667-72$.

(122) Viriyakosol S, Kirkland T, Soldau K, Tobias P. MD-2 binds to bacterial lipopolysaccharide. J Endotoxin Res 2000;6(6):489-91.

(123) Macagno A, Molteni M, Rinaldi A, Bertoni F, Lanzavecchia A, Rossetti C, et al. A cyanobacterial LPS antagonist prevents endotoxin shock and blocks sustained TLR4 stimulation required for cytokine expression. J Exp Med 2006 Jun 12;203(6):1481-92. 
(124) Jemmett K, Macagno A, Molteni M, Heckels JE, Rossetti C, Christodoulides M. A cyanobacterial lipopolysaccharide antagonist inhibits cytokine production induced by Neisseria meningitidis in a human whole-blood model of septicemia. Infect Immun $2008 \mathrm{Jul} ; 76(7): 3156-63$.

(125) Thorgersen EB, Macagno A, Rossetti C, Mollnes TE. Cyanobacterial LPS antagonist (CyP)-A novel and efficient inhibitor of Escherichia coli LPSinduced cytokine response in the pig. Mol Immunol 2008 Jun 18.

(126) McDonagh S, Maidji E, Ma W, Chang HT, Fisher S, Pereira L. Viral and bacterial pathogens at the maternal-fetal interface. J Infect Dis 2004 Aug 15;190(4):826-34.

(127) Marchini G, Nelson A, Edner J, Lonne-Rahm S, Stavreus-Evers A, Hultenby $\mathrm{K}$. Erythema toxicum neonatorum is an innate immune response to commensal microbes penetrated into the skin of the newborn infant. Pediatr Res 2005 Sep;58(3):613-6.

(128) Karlsson H, Hessle C, Rudin A. Innate immune responses of human neonatal cells to bacteria from the normal gastrointestinal flora. Infect Immun 2002 Dec;70(12):6688-96.

(129) Adkins B, Leclerc C, Marshall-Clarke S. Neonatal adaptive immunity comes of age. Nat Rev Immunol 2004 Jul;4(7):553-64.

(130) Adkins B. Development of neonatal Th1/Th2 function. Int Rev Immunol 2000;19(2-3):157-71.

(131) Cohen L, Haziot A, Shen DR, Lin XY, Sia C, Harper R, et al. CD14independent responses to LPS require a serum factor that is absent from neonates. J Immunol 1995 Dec 1;155(11):5337-42.

(132) Angelone DF, Wessels MR, Coughlin M, Suter EE, Valentini P, Kalish LA, et al. Innate immunity of the human newborn is polarized toward a high ratio of IL-6/TNF-alpha production in vitro and in vivo. Pediatr Res 2006 Aug;60(2):205-9.

(133) Levy O. Innate immunity of the human newborn: distinct cytokine responses to LPS and other Toll-like receptor agonists. J Endotoxin Res 2005;11(2):1136.

(134) Levy E, Xanthou G, Petrakou E, Zacharioudaki V, Tsatsanis C, Fotopoulos S, et al. Distinct roles of TLR4 and CD14 in LPS-induced inflammatory responses of neonates. Pediatr Res 2009 Aug;66(2):179-84.

(135) Sonntag J, Brandenburg U, Polzehl D, Strauss E, Vogel M, Dudenhausen JW, et al. Complement system in healthy term newborns: reference values in umbilical cord blood. Pediatr Dev Pathol 1998 Mar;1(2):131-5.

(136) Wolach B, Dolfin T, Regev R, Gilboa S, Schlesinger M. The development of the complement system after 28 weeks' gestation. Acta Paediatr 1997 May;86(5):523-7. 
(137) Tollofsrud PA, Medbo S, Solas AB, Drevon CA, Saugstad OD. Albumin mixed with meconium attenuates pulmonary dysfunction in a newborn piglet model with meconium aspiration. Pediatr Res 2002 Oct;52(4):545-53.

(138) Lindenskov PH, Castellheim A, Aamodt G, Saugstad OD. Meconium induced IL-8 production and intratracheal albumin alleviated lung injury in newborn pigs. Pediatr Res 2005 Mar;57(3):371-7.

(139) Mollnes TE, Brekke OL, Fung M, Fure H, Christiansen D, Bergseth G, et al. Essential role of the $\mathrm{C} 5 \mathrm{a}$ receptor in $\mathrm{E}$ coli-induced oxidative burst and phagocytosis revealed by a novel lepirudin-based human whole blood model of inflammation. Blood 2002 Sep 1;100(5):1869-77.

(140) Undar A, Eichstaedt HC, Clubb FJ, Jr., Fung M, Lu M, Bigley JE, et al. Novel anti-factor D monoclonal antibody inhibits complement and leukocyte activation in a baboon model of cardiopulmonary bypass. Ann Thorac Surg 2002 Aug;74(2):355-62.

(141) Fung M, Loubser PG, Undar A, Mueller M, Sun C, Sun WN, et al. Inhibition of complement, neutrophil, and platelet activation by an anti-factor D monoclonal antibody in simulated cardiopulmonary bypass circuits. J Thorac Cardiovasc Surg 2001 Jul;122(1):113-22.

(142) Zhao H, Wakamiya N, Suzuki Y, Hamonko MT, Stahl GL. Identification of human mannose binding lectin (MBL) recognition sites for novel inhibitory antibodies. Hybrid Hybridomics 2002 Feb;21(1):25-36.

(143) Collard CD, Vakeva A, Morrissey MA, Agah A, Rollins SA, Reenstra WR, et al. Complement activation after oxidative stress: role of the lectin complement pathway. Am J Pathol 2000 May;156(5):1549-56.

(144) Voller A, Bartlett A, Bidwell DE. Enzyme immunoassays with special reference to ELISA techniques. J Clin Pathol 1978 Jun;31(6):507-20.

(145) Leng SX, McElhaney JE, Walston JD, Xie D, Fedarko NS, Kuchel GA. ELISA and multiplex technologies for cytokine measurement in inflammation and aging research. J Gerontol A Biol Sci Med Sci 2008 Aug;63(8):879-84.

(146) Mollnes TE, Lea T, Harboe M. Detection and quantification of the terminal C5b-9 complex of human complement by a sensitive enzyme-linked immunosorbent assay. Scand J Immunol 1984 Aug;20(2):157-66.

(147) Mollnes TE, Lea T, Froland SS, Harboe M. Quantification of the terminal complement complex in human plasma by an enzyme-linked immunosorbent assay based on monoclonal antibodies against a neoantigen of the complex. Scand J Immunol 1985 Aug;22(2):197-202.

(148) Fure H, Nielsen EW, Hack CE, Mollnes TE. A neoepitope-based enzyme immunoassay for quantification of $\mathrm{C} 1$-inhibitor in complex with $\mathrm{C} 1 \mathrm{r}$ and $\mathrm{C} 1 \mathrm{~s}$. Scand J Immunol 1997 Dec;46(6):553-7. 
(149) Seelen MA, Roos A, Wieslander J, Mollnes TE, Sjoholm AG, Wurzner R, et al. Functional analysis of the classical, alternative, and MBL pathways of the complement system: standardization and validation of a simple ELISA. J Immunol Methods 2005 Jan;296(1-2):187-98.

(150) Fredrikson GN, Truedsson L, Sjoholm AG. New procedure for the detection of complement deficiency by ELISA. Analysis of activation pathways and circumvention of rheumatoid factor influence. J Immunol Methods 1993 Dec 3;166(2):263-70.

(151) Mollnes TE, Redl H, Hogasen K, Bengtsson A, Garred P, Speilberg L, et al. Complement activation in septic baboons detected by neoepitope-specific assays for $\mathrm{C} 3 \mathrm{~b} / \mathrm{iC} 3 \mathrm{~b} / \mathrm{C} 3 \mathrm{c}, \mathrm{C} 5 \mathrm{a}$ and the terminal C5b-9 complement complex (TCC). Clin Exp Immunol 1993 Feb;91(2):295-300.

(152) Hannon JP, Bossone CA, Wade CE. Normal physiological values for conscious pigs used in biomedical research. Lab Anim Sci 1990 May;40(3):293-8.

(153) Fay RS, Gallant EM. Halothane sensitivity of young pigs in vivo and in vitro. Am J Physiol 1990 Jul;259(1 Pt 2):R133-R138.

(154) Hodgson DS. Comparison of isoflurane and sevoflurane for short-term anesthesia in piglets. Vet Anaesth Analg 2007 Mar;34(2):117-24.

(155) Mutoh T, Nishimura R, Kim HY, Matsunaga S, Sasaki N. Cardiopulmonary effects of sevoflurane, compared with halothane, enflurane, and isoflurane, in dogs. Am J Vet Res 1997 Aug;58(8):885-90.

(156) Strom J, Haggmark S, Reiz S, Sorensen MB. Cardiovascular effects of pentobarbital in pigs, and the lack of response to naloxone in pentobarbital induced circulatory failure. Acta Anaesthesiol Scand 1987 Jul;31(5):413-6.

(157) Swindle MM, Smith AC, Hepburn BJ. Swine as models in experimental surgery. J Invest Surg 1988;1(1):65-79.

(158) Moon PF, Scarlett JM, Ludders JW, Conway TA, Lamb SV. Effect of fentanyl on the minimum alveolar concentration of isoflurane in swine. Anesthesiology 1995 Sep;83(3):535-42.

(159) Smith AC, Zellner JL, Spinale FG, Swindle MM. Sedative and cardiovascular effects of midazolam in swine. Lab Anim Sci 1991 Apr;41(2):157-61.

(160) Yoder BA, Gordon MC, Barth WH, Jr. Late-preterm birth: does the changing obstetric paradigm alter the epidemiology of respiratory complications? Obstet Gynecol 2008 Apr;111(4):814-22.

(161) Katz VL, Bowes WA, Jr. Meconium aspiration syndrome: reflections on a murky subject. Am J Obstet Gynecol 1992 Jan;166(1 Pt 1):171-83.

(162) Brekke OL, Christiansen D, Fure H, Fung M, Mollnes TE. The role of complement $\mathrm{C} 3$ opsonization, $\mathrm{C} 5 \mathrm{a}$ receptor, and CD14 in E. coli-induced up- 
regulation of granulocyte and monocyte CD11b/CD18 (CR3), phagocytosis, and oxidative burst in human whole blood. J Leukoc Biol 2007

Jun;81(6):1404-13.

(163) Brekke OL, Christiansen D, Fure H, Pharo A, Fung M, Riesenfeld J, et al. Combined inhibition of complement and CD14 abolish E. coli-induced cytokine-, chemokine- and growth factor-synthesis in human whole blood. Mol Immunol 2008 Jul 5.

(164) Levy RM, Prince JM, Yang R, Mollen KP, Liao H, Watson GA, et al. Systemic inflammation and remote organ damage following bilateral femur fracture requires Toll-like receptor 4. Am J Physiol Regul Integr Comp Physiol 2006 Oct;291(4):R970-R976.

(165) Sprong T, Moller AS, Bjerre A, Wedege E, Kierulf P, van der Meer JW, et al. Complement activation and complement-dependent inflammation by Neisseria meningitidis are independent of lipopolysaccharide. Infect Immun 2004 Jun;72(6):3344-9.

(166) Zhang H, Li J, Barrington RA, Liang G, Qin G, Liu DX. An anti-endotoxin peptide that generates from the amino-terminal domain of complement regulatory protein $\mathrm{C} 1$ inhibitor. Biochem Biophys Res Commun 2007 Jul 27;359(2):285-91.

(167) Miyake K. Innate immune sensing of pathogens and danger signals by cell surface Toll-like receptors. Semin Immunol 2007 Feb;19(1):3-10.

(168) Bessler H, Komlos L, Punsky I, Ntambi JA, Bergman M, Straussberg R, et al. CD14 receptor expression and lipopolysaccharide-induced cytokine production in preterm and term neonates. Biol Neonate 2001;80(3):186-92.

(169) Juul-Madsen HR, Krogh-Meibom T, Henryon M, Palaniyar N, Heegaard PM, Purup $\mathrm{S}$, et al. Identification and characterization of porcine mannan-binding lectin A (pMBL-A), and determination of serum concentration heritability. Immunogenetics 2006 Apr;58(2-3):129-37. 
9 PAPERS 

This article is removed. 




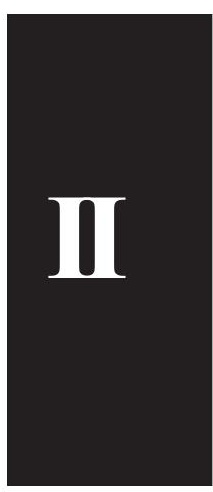


This article is removed. 




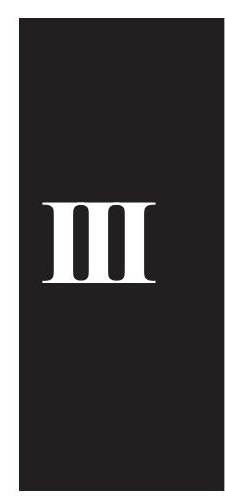


This article is removed. 



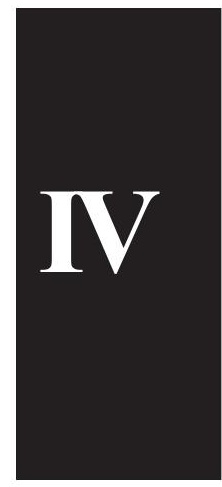





\section{Meconium-induced release of cytokines is mediated by the}

\section{TRL4/MD-2 complex in a CD14-dependent manner}

Bodil Salvesen ${ }^{1,2}$ Jørgen Stenvik $^{3}$, Carlo Rossetti ${ }^{4}$, Ola D. Saugstad ${ }^{2}$, Terje Espevik $^{3}$ and Tom E. Mollnes ${ }^{1}$

\section{Authors affiliations:}

Bodil Salvesen, ${ }^{1}$ Institute of Immunology and ${ }^{2}$ Department of Pediatric Research, Medical Faculty, University of Oslo and Rikshospitalet University Hospital, Oslo, Norway

Jørgen Stenvik, ${ }^{3}$ Institute of Cancer Research and Molecular Medicine, Norwegian University of Science and Technology, Trondheim, Norway

Carlo Rossetti, ${ }^{4}$ Department of Biotechnology and Molecular Sciences, University of Insubria, Via Dunant 3, 21100 Varese, Italy

Ola Didrik Saugstad, ${ }^{2}$ Department of Pediatric Research, Medical Faculty, University of Oslo and Rikshospitalet University Hospital, Oslo, Norway

Terje Espevik, ${ }^{3}$ Institute of Cancer Research and Molecular Medicine, Norwegian University of Science and Technology, Trondheim, Norway

Tom Eirik Mollnes, ${ }^{1}$ Institute of Immunology, University of Oslo and Rikshospitalet University Hospital, Oslo, Norway

\section{Corresponding author:}

Bodil Salvesen, Department of Pediatric Research, Barneklinikken, Rikshospitalet, 0027 Oslo, Norway 


\section{Abbreviations}

ANOVA - analysis of variance, basic FGF - fibroblast growth factor, CI - confidence interval, CyP - cyanobacterial product, DAMPs - damage/danger associated molecular patterns, GM-CSF - granulocyte macrophage colony-stimulating factor, GCSF - granulocyte colony-stimulating factor, HEK cells - human embryonic kidney cells, IFN- $\gamma$ - interferon-gamma, IgG - immunoglobulin G, IL - interleukin, IP-10 interferon- $\gamma$-inducible protein 10, LPS - lipopolysaccharide, mAb - monoclonal antibody, MAS - meconium aspiration syndrome, MCP-1 - monocyte chemotactic protein-1, MD-2 - myeloid differentiation protein-2, MIP-1 $\alpha$ - macrophage inhibitory protein-1 $\alpha$, NFкB - nuclear factor kappa-light-chain enhancer of activated B-cells, PAMPs - pathogen associated molecular patterns, PRR - pathogen recognition receptor, PBS - phosphated buffered saline, RANTES - regulated upon activation, normal T cell expressed and secreted, TNF- $\alpha$ - tumor necrosis factor-alpha, TLR - toll like receptor, VEGF - vascular endothelial growth factor .

\section{Keywords}

CD14, CyP, cytokines, inflammation, lipopolysaccharide, MD-2, meconium, Toll-like receptor. 


\section{ABSTRACT}

\section{OBJECTIVE}

Meconium, the first intestinal discharge of the newborn, contains material accumulated during fetal life. Meconium activates complement and CD14 and may induce a systemic inflammatory response. Toll-like receptors are classical patternrecognition receptors recognizing both exogenous and host derived ligands. The cyanobacterial product CyP is a potent LPS antagonist binding to the TLR4/MD-2 complex. The aim of the present study was to investigate the role of the CD14/TLR4/MD-2 complex in meconium-induced inflammation.

\section{METHODS}

Whole blood from six donors was preincubated with anti-CD14 or CyP. Meconium was added and the samples were incubated for four hours. Twenty-seven inflammatory mediators were measured in a Bioplex Array Reader. Human embryonic kidney cells transfected with plasmids containing NF-kB dependent luciferase reporter, human MD-2, TLR4, TLR2 and/or CD14, were incubated with meconium or LPS for 18 hours. Luciferase activity in cytoplasmic extracts was measured using a Luciferase Assay System kit.

\section{RESULTS}

Meconium induced formation of a broad panel of inflammatory mediators. CyP and anti-CD14 significantly $(\mathrm{p}<0.001)$ inhibited meconium-induced formation of a) proinflammatory cytokines (TNF- $\alpha$, IL-1 $\beta$, IL-6, IFN- $\gamma$ ) by $60-80 \%$ and $72-94 \%$, respectively, b) anti-inflammatory cytokines (IL-10, IL-1Ra) by 58-59\% and 50-65\%, respectively, c) chemokines (IL-8, MCP-1, MIP-1 $\alpha$, MIP-1 $\beta$, eotaxin, IP-10) by 43$77 \%$ and $57-87 \%$, respectively, and d) growth factors (G-CSF, GM-CSF, basic FGF, 
PDGFbb) by 53-71\% and 40-78\%, respectively, with no statistical significant difference between Cyp and anti-CD14. The inflammatory response could only partly be explained by LPS, suggesting that endogenous components of meconium contribute to the inflammatory response. Meconium activated NF-kB dosedependently in cells expressing TLR4/MD-2 together with CD14, while no effect was seen in cells expressing TLR4/MD-2 alone or in TLR2/CD14 transfected cells.

\section{CONCLUSIONS}

The results indicate that the CD14-dependent meconium-induced inflammatory reaction is mediated through the TLR4/MD2 complex. These data may have implications for future therapeutic strategies for meconium aspiration syndrome. 


\section{INTRODUCTION}

Meconium, the first intestinal discharge, represents material accumulated during fetal life, like secretions from salivary and intestinal glands like mucus, bile and bile acids, fatty acids and steroids from the gut, cellular debris, lanugo hair, components from vernix caseosa, amniotic fluid, and blood (Antonowicz and Shwachman, 1979). Meconium aspiration syndrome (MAS), a serious disease in newborns including aspiration of meconium into the lungs, has a complex, not well defined pathophysiology (Cleary and Wiswell, 1998;Dargaville and Copnell, 2006). The complement system and Toll-like receptors (TLR), including the CD14-associated TLR4/MD-2 complex, are two important components of the innate immune system, which both act upstream and partly independently (Uthaisangsook et al., 2002). We have earlier shown that meconium is an important activator of complement (Castellheim et al., 2004;Mollnes et al., 2008) as well as of the CD14-mediated inflammatory reaction reflected by synthesis of a broad spectrum of cytokines, chemokines and growth factors in human whole blood and in cord blood (Salvesen et al., 2008). Inhibition of either CD14 or the complement system reduced the meconium-induced formation of most inflammatory mediators, but the combined inhibition of both systems had a remarkable effect indicating a synergistic effect of inhibition of both these two main branches of innate immunity.

The innate immune system recognizes highly conserved structures present on large numbers of microorganisms referred to as pathogen-associated molecular patterns (PAMPs). These exogenous ligands include bacterial lipopolysaccharide (LPS), peptidoglycan, lipotheichoic acids, mannan, zymosan, double stranded RNA, bacterial 
DNA and glucans (Janeway, Jr. and Medzhitov, 2002). Host-derived immunostimulators, i.e. endogenous ligands, like heparan sulphate, hyaluronan, heatshock proteins, surfactant proteins, uric acid, fibronectin, $\beta$-defensin and cardiolipin may also signal through the same receptors as PAMPs (Levy et al., 2006; Gay and Gangloff, 2007), and was originally termed damage-associated molecular patterns (DAMPs) (Seong and Matzinger, 2004;Matzinger, 1994). Recent years DAMP has alternatively been used as abbreviation for "danger-associated molecular patterns", covering the general phenomenon of danger signaling of both exogenous and endogenous ligands.

Pattern recognition receptors (PRRs) recognize structural patterns on exogenous as well as endogenous ligands (Medzhitov and Janeway, Jr., 2000). The classical PRRs are the toll-like receptors (TLRs). TLR4, TLR1, 2, and 6 are found on the plasma membrane of immune cells and recognize lipoproteins and lipoglycans on the surface of microbes. All TLRs except TLR3 signal through the MyD88 pathway leading to activation of the $\mathrm{NF} \kappa \mathrm{B}$ gene-transcription program and formation of proinflammatory cytokines. TLR4-mediated LPS recognition depend on the protein MD-2, which forms a complex with the ectodomain of TLR4 (Shimazu et al., 1999). The TLR4/MD-2 complex engages with LPS on cell surfaces via LPS-binding protein (LBP) and CD14 (Kawai and Akira, 2009). In addition to being essential for TLR4 function, the CD14 molecule, but not MD-2, is also involved in the function of TLR2 (Muta and Takeshige, 2001;Nilsen et al., 2008) and TLR3 (Lee et al., 2006).

The cyanobacterial product (CyP), a LPS-like molecule derived from the cyanobacterium Oscillatoria Planktotrix FP1, is a potent and selective antagonist of 
bacterial LPS in vitro and in vivo by its competitive binding to the TLR4/MD-2complex (Macagno et al., 2006).

The aim of the present study was to investigate the role of the TLR4/MD-2 complex in meconium-induced inflammation by comparing the effect of MD-2 inhibition by $\mathrm{CyP}$ with CD14 inhibition in human whole blood and to investigate the involvement of CD14, MD-2, TLR4 and TLR2 in human transfected cell lines. The results unequivocally indicate that the CD14-mediated meconium-induced inflammatory reaction is mediated through the TLR4/MD-2 complex. 


\section{METHODS}

\section{Reagents and Equipment}

All materials and solutions were endotoxin-free according to the manufacturers. Sterile phosphate-buffered saline (PBS) was Dulbecco (Sigma-Aldrich, Oslo, Norway). Propylene tubes were NUNC cryotubes (Nalgene NUNC, Roskilde, Denmark). Lepirudin (Refludan ${ }^{\circledR}$ ) was from Hoechst (Frankfurt am Main, Germany).

\section{Antibodies and other Reagents}

Mouse anti-human CD14 (clone18D11) was purchased from Diatec (Oslo, Norway).

\section{CyP}

CyP was purified from the freshwater cyanobacterium Oscillatoria planktothrix FP1 by a phenol-guanidium thiocyanate-based method as described previously (Macagno et al., 2006).

\section{Preparation of meconium and the endotoxin assay}

Meconium was collected and processed as previously described (Salvesen et al., 2008). No bacteria were detected after cultivation. The endotoxin or LPS content in meconium was analyzed in a Pyrochrome ${ }^{\circledR}$ Limulus Amoebocyte Lysate assay by an endpoint chromogenic method using a diazo-coupling assay kit (Associates of CAPE COD, Inc., Falmouth, MA). Meconium samples were diluted in depyrogenated Pyrotube-D ${ }^{\circledR}$ tubes with LAL Reagent water (both Associates of CAPE COD, Inc., Liverpool, UK). The diluted samples were heated to $75^{\circ} \mathrm{C}$ for 10 minutes, mixed with pyrochrome solved in Glucashield ${ }^{\circledR}$, a $\beta$-glucan inhibiting buffer, and incubated in a 96-well Pyroplate ${ }^{\circledR}$ (both Associates of CAPE COD, Inc., Falmouth, MA) on a dry 
block incubator. The assay was performed according to instructions from the manufacturer. The LPS content in the meconium was found to be $30 \mathrm{EU} / \mathrm{mg}$ meconium, corresponding to $3 \mathrm{ng} / \mathrm{mg}$ meconium.

\section{Experimental Set-up}

\section{Titration of $C y P$}

To investigate the optimal concentration of $\mathrm{CyP}$ needed in the following experiments, human whole blood anticoagulated with lepirudin at $50 \mu \mathrm{g} / \mathrm{mL}$ (Mollnes et al., 2002), was collected from two adult healthy donors and distributed into tubes containing PBS and CyP, the latter diluted two-fold from $20 \mu \mathrm{g} / \mathrm{mL}$ to $0.156 \mu \mathrm{g} / \mathrm{mL}$ whole blood. The samples were preincubated for five minutes before adding either PBS or a high dose of meconium (1mg/mL) (Salvesen et al., 2008). Baseline sample (T0), containing only blood and PBS was processed immediately while the other samples were incubated for four hours at $37^{\circ} \mathrm{C}$. Negative control samples after four hours (T4) contained blood and PBS. At the end of the incubation ethylenediaminetetraacetic acid (EDTA) was added to all samples to a final concentration of $20 \mathrm{mM}$ to avoid further complement activation. Then the tubes were centrifuged for 15 minutes at $1400 \times g\left(4^{\circ} \mathrm{C}\right)$. The plasma samples were stored at $-70^{\circ} \mathrm{C}$ until assayed as described below. Based on these results a CyP concentration of $20 \mu \mathrm{g} / \mathrm{mL}$ was chosen for the subsequent meconium experiments.

\section{Titration of Meconium}

The effect of CyP on cytokine release over a range of meconium concentration was then investigated. Human whole blood from two adult healthy donors was collected and handled as describe above. The samples were preincubated for five minutes with 
PBS or CyP $20 \mu \mathrm{g} / \mathrm{mL}$ before adding meconium in increasing concentrations $(0.003$, $0.01,0.03,0.1,0.3$ and $1 \mathrm{mg} / \mathrm{mL}$ whole blood). Baseline sample (T0), containing only blood and PBS was processed immediately while the other samples were incubated for four hours at $37^{\circ} \mathrm{C}$. Negative control samples (T4) contained blood and PBS. At the end of the incubation ethylenediaminetetraacetic acid (EDTA) was added to all samples to a final concentration of $20 \mathrm{mM}$ to avoid further complement activation. Then the tubes were centrifuged for 15 minutes at $1400 \times g\left(4^{\circ} \mathrm{C}\right)$. The plasma samples were stored at $-70^{\circ} \mathrm{C}$ until assayed as described below. Based on these results two different meconium concentrations $(0.1$ and $1 \mathrm{mg} / \mathrm{mL}$ whole blood $)$ were chosen for the subsequent serial analyses.

\section{Effect of $C y P$ and anti-CD14 on the meconium-induced inflammatory reaction}

Human whole blood from six adult healthy donors was obtained as described above. The samples were distributed into tubes containing PBS, CyP $(20 \mu \mathrm{g} / \mathrm{mL}$ blood), inhibitory anti-CD14 antibody $(100 \mu \mathrm{g} / \mathrm{mL}$ blood), or a negative control (isotypematched antibody). The samples were preincubated for five minutes before adding either PBS or meconium 0.1 or $1 \mathrm{mg} / \mathrm{mL}$ whole blood. Baseline sample (T0), containing only blood and PBS was processed immediately while the other samples were incubated for four hours at $37^{\circ} \mathrm{C}$. Negative control sample (T4) contained blood and PBS. At the end of the incubation ethylenediaminetetraacetic acid (EDTA) was added to all samples to a final concentration of $20 \mathrm{mM}$ to avoid further complement activation. Then the tubes were centrifuged for 15 minutes at $1400 \times g\left(4^{\circ} \mathrm{C}\right)$. The plasma samples were stored at $-70^{\circ} \mathrm{C}$ until assayed as described below. Both meconium concentrations induced a marked inflammatory response, reflecting the dose-response effect observed in the titration studies. The inhibitory effect of CyP and 
anti-CD14 were similar for both concentrations and the results for meconium 0.1 $\mathrm{mg} / \mathrm{mL}$ are presented.

\section{Cytokine Analysis}

The following cytokines, chemokines and growth factors were measured on a Bioplex Array Reader (LUMINEX 100, Bio-Rad Laboratories, Hercules, CA) using Bio-Plex Human Cytokine 27-plex panel (Bio-Rad Laboratories, Hercules, CA): IL-1Ra, IL-1ß, IL-2, IL-4, IL-5, IL-6, IL-7, IL-8, IL-9, IL-10, IL-12p70, IL-13, IL-15, IL-17, TNF- $\alpha$, IFN- $\gamma$, MIP- $1 \alpha$, MIP-1 $\beta$, eotaxin, MCP-1, G-CSF, GM-CSF, basic FGF, VEGF, IP10, RANTES, and PDGFbb.

\section{Transient transfection and NF-kB Luciferase assay}

This assay has been described in detail previously (Hellerud et al., 2008). Human embryonic kidney (HEK) 293 cells (American Type Culture Collection, Manassas, VA) were grown in Dulbecco's modified Eagle's medium (DMEM) supplemented with $10 \%$ fetal calf serum (FCS, Euroclone, Milano, Italy), L-glutamine and 10ug/ml ciprofloxacin (Cellgro, Manassas, VA) at $37^{\circ} \mathrm{C}$ and $8 \% \mathrm{CO}_{2}$. Transient transfection

was done using GeneJuice ${ }^{\mathrm{TM}}$ transfection reagent (Novagen, Merck KGaA, Darmstadt, Germany) according to the manufacturer's protocol. In short, cells were plated at a cell density of $1 \times 10^{4}$ cells/well in 96-well dishes and grown to $50 \%$ confluency. Plasmids used were the NF-kB dependent luciferase reporter plasmid pELAM-luc (Chow et al., 1999), human CD14 in pcDNA3 kindly provided by Dr. D. Golenbock (University of Massachusetts Medical School), human MD-2 in pEFBOS kindly provided by Dr. K. Miyake (University of Tokyo), human TLR4 in pcDNA3 kindly provided by Drs. R. Medzhitov and C. Janeway (Yale University, New Haven, 
CT), and human TLR2 in pRK7 kindly provided by Dr. C. Kirschning (Technical University of Munich). A dosage of $25 \mathrm{ng} /$ well of each plasmid was used for transfection and pcDNA3 (Invitrogen Corp., Carlsbad, CA) was used to adjust the total amount of plasmid to $100 \mathrm{ng} /$ well. All plasmids were isolated using the EndoFree plasmid kit (Qiagen Inc., Valencia CA). After transfection for 24 hours, the cells were stimulated for 18 hours with meconium $(0.01-100 \mu \mathrm{g} / \mathrm{mL})$ or LPS $(0.1-1000 \mathrm{ng} / \mathrm{mL})$. HEK293 cells stably transfected with TLR9 were provided by Eisai Pharmaceuticals (Andover, MA). The positive controls were stimulated with $10 \mu \mathrm{M}$ phosphothioate CpG DNA 2006 (Tib Molbiol, Berlin, Germany). Cytoplasmic extracts were prepared and luciferase activity was measured using the Luciferase Assay System kit according to the manufacturer's recommendations (Promega, Madison, WI) and Victor ${ }^{3 \mathrm{TM}} 1420$ multilabel counter (Perkin Elmer, Waltham, MA). Ultra pure E. coli LPS 0111:B4 was from ordered from Invivogen (San Diego, CA) and fibroblast stimulating lipopeptide (FLS-1) was ordered from EMC Microcollections GMBH (Tübingen, Germany).

\section{Data Presentation and Statistics}

Data from the titration of $\mathrm{CyP}$ and meconium $(\mathrm{n}=2)$ are presented as mean with range. Data from the inhibition experiment with CyP and anti-CD14 $(n=6)$ are presented as mean with $95 \%$ confidence interval (CI). Data from the inhibition experiment are compared using repeated measurements ANOVA with Tukey as a post test. A twotailed p-value below 0.05 was considered significant. Results from the transfection cell assay are presented as triplicate (duplicates for TLR9-transfected cells) and are given as fold induction relative to the PBS treated control. 


\section{Ethics}

Informed consent was obtained from all donors. The study was approved by the Norwegian Regional Ethical Committee. 


\section{RESULTS}

\section{Dose-dependent effect of CyP on meconium-induced inflammation}

Increasing concentrations of CyP from 0.156- $20 \mu \mathrm{g} / \mathrm{mL}$ whole blood dosedependently inhibited meconium-induced formation of TNF- $\alpha$, IL-6, IFN- $\gamma$, and IL-8 (Fig.1). CyP efficiently inhibited the cytokine release even at low doses and maximum inhibition was generally reached at $5-10 \mu \mathrm{g} / \mathrm{mL}$. Maximum inhibition for IL-8 was reached at $2.5 \mu \mathrm{g} / \mathrm{mL}$ and thereafter an apparently slight increase was observed.

\section{Effect of CyP on inflammation induced by different doses of meconium}

Based on the results obtained in the experiments described in Fig.1, a fixed dose of CyP $(20 \mu \mathrm{g} / \mathrm{mL})$ was used for inhibition experiments using increasing concentrations of meconium from 0.003 to $1 \mathrm{mg} / \mathrm{mL}$ whole blood. A sub-maximal response of cytokine release was reached using $0.1 \mathrm{mg}$ meconium $/ \mathrm{mL}$ blood and thereafter a slight increase was observed up to $1 \mathrm{mg} / \mathrm{mL}$ (Fig.2). CyP very efficiently inhibited the release of TNF- $\alpha$, IL-1 $\beta$ and IL-6 over the whole range of meconium concentration, and markedly reduced the formation of IL-8 although not completely at high meconium concentrations.

\section{Effect of CyP and anti-CD14 on meconium-induced inflammation}

Based on the titration data obtained above, whole blood from six healthy blood donors was incubated with meconium at 0.1 and $1 \mathrm{mg} / \mathrm{mL}$ whole blood and the effect of CyP $(20 \mu \mathrm{g} / \mathrm{mL})$ and anti-CD14 $(100 \mathrm{ug} / \mathrm{mL})$ on the cytokine release was investigated. Twenty-one of the 27 inflammatory mediators measured were induced by incubation with meconium: IL-1Ra, IL-1ß, IL-2, IL-4, IL-6, IL-8, IL-10, IL-12p70, IL-15, IL-17, 
TNF- $\alpha$, IFN- $\gamma$, MIP-1 $\alpha$, MIP-1 $\beta$, eotaxin, MCP-1, G-CSF, GM-CSF, basic FGF, IP10, and PDGFbb. Data from 16 of these are presented below. Consistent with the results presented in Fig.2, there was a modest dose-dependent difference between meconium 0.1 and $1 \mathrm{mg} / \mathrm{mL}$ with respect to the inflammatory response. The effect of CyP and anti-CD14 were, however, similar using both doses of meconium. The results for meconium $0.1 \mathrm{mg} / \mathrm{mL}$ are shown below.

\section{Proinflammatory Cytokines}

The substantial meconium-induced formation of TNF- $\alpha$, IL-1 $\beta$, IL- 6 , and IFN- $\gamma$ was significantly reduced by CyP (60-80\%) and by anti-CD14 (72-94\%) $(\mathrm{p}<0.0001$ for all) (Fig.3, upper four panels). There was no statistical difference between CyP and anti-CD14.The same pattern was also found for IL-2, IL-12p70, IL-15 and IL-17 (data not shown).

\section{Anti-inflammatory Cytokines}

The substantial meconium-induced formation of IL-10 and IL-1Ra was significantly reduced by CyP (58-59\%) and by anti-CD14 (50-65\%) (p <0.0001 for all) (Fig.3, lower two panels). There was no statistical difference between CyP and anti-CD14. The same pattern was also found for IL-4 (data not shown).

\section{Chemokines}

The substantial meconium-induced formation of IL-8, MCP-1, MIP-1 $\alpha$, MIP-1 $\beta$, eotaxin, and IP-10 was significantly reduced by CyP (43-77\%) and anti-CD14 (57$87 \%$ ) ( $\mathrm{p}<0.0001$ for all) (Fig.4). There was no statistical difference between CyP and anti-CD14. 


\section{Growth Factors}

The substantial meconium-induced formation of G-CSF, GM-CSF, basic FGF, and PDGFbb was significantly reduced by CyP (53-71\%) and by anti-CD14 (40-78\%) $(\mathrm{p}<0.0001$ for G-CSF, GM-CSF, basic FGF, $\mathrm{p}=0.0003$ for PDGFbb) (Fig.5). There was no statistical difference between $\mathrm{CyP}$ and anti-CD14.

\section{Activation of NF- $k$ B by meconium in transfected HEK293 cells}

Meconium activated NF- $k$ B dose dependently from 1-100ug/ml in HEK293 cells expressing TLR4/MD-2 together with CD14, while virtually no response was seen when the cells were transfected with TLR4/MD-2 alone (Fig.6, left panel). CD14 enhanced the efficacy of LPS stimulation at low LPS concentrations, but as the LPSconcentration increased the effect of CD14 decreased (Fig.6, left panel). The TLR2mediated activation of NF- $k \mathrm{~B}$ by meconium was negligible whether or not CD14 was co-expressed (Fig. 6, middle panel), and meconium did not activate NF- $k$ B through TLR9 (Fig.6, right panel). No response was seen in cells transfected with NF- $k$ B luciferase and empty vector (not shown). 


\section{DISCUSSION}

In this study we demonstrate for the first time that meconium-induced cytokine, chemokine and growth factor formation is mainly mediated through the TLR4/MD-2 complex as shown by a substantial inhibition of the biomarker release using the LPS antagonist CyP. Furthermore, we documented the requirement of CD14 for this response using transfected cells. Thus, the previously observed CD14-dependency of meconium-induced cytokine formation (Salvesen et al., 2008) can be attributed to signaling via the CD14/TLR4/MD-2 complex.

We have previously shown that meconium induced a potent CD14-mediated inflammatory reaction reflected by synthesis of several inflammatory mediators (Salvesen et al., 2008) and also activated the second main branch of the innate immune system, the complement system, via the lectin and alternative pathways (Salvesen et al., 2009; Castellheim et al., 2004;Salvesen et al., 2009) in both cord and adult whole blood. A combined inhibition of CD14 and complement in meconiuminduced inflammation showed a remarkable effect on virtually all of the mediators measured (Salvesen et al., 2008), indicating a synergistic effect of blocking these two main branches of innate immunity on the inflammatory response induced by meconium. CyP activates complement dose-dependently from $25 \mu \mathrm{g} / \mathrm{mL}$ whole blood (Thorgersen et al., 2008). A maximum inhibitory effect of CyP on cytokine formation in the present study was obtained at concentrations below $10 \mu \mathrm{g} / \mathrm{mL}$, i.e. below the complement activation potential of CyP. IL-8 was most efficiently inhibited at $2.5 \mu \mathrm{g} / \mathrm{mL}$. Collectively, our data indicate an optimal cytokine-inhibitory effect at CyP concentrations of approximately $5 \mu \mathrm{g} / \mathrm{mL}$ whole blood. 
In the present study we investigated the mechanism of the CD14-dependent meconium-induced inflammatory reaction. MD-2 is a necessary cofactor for TLR4 in the detection of LPS and this process is greatly enhanced by CD14 and LPS-binding protein (Perera et al., 1997) (Nagai et al., 2002). Soluble MD-2 binds LPS directly with high affinity and the LPS/MD-2 complex forms a ligand that activates TLR4 positive cells (Viriyakosol et al., 2000). CyP binds directly to the TLR4/MD-2 complex and competitively inhibits binding to LPS (Macagno et al., 2006). CyP protects mice from lethal LPS-induced shock and exerts its inhibitory activity in dendritic cells even if added several hours after LPS. CyP is a potent antagonist of meningococcal LPS (Jemmett et al., 2008) and an efficient inhibitor of E. coli LPSinduced cytokine release (Thorgersen et al., 2008). In the present study CyP decreased the meconium-induced formation of most mediators measured considerably and to virtually the same extent as anti-CD14, suggesting that the CD14-dependent effect of meconium-induced inflammation is mediated solely through the TLR4/MD2 complex.

TLR4 is an important mediator of inflammation and tissue damage (Miyake, 2007). Meconium activated NF- $k$ B dose-dependently in HEK293 cells expressing TLR4/MD-2 together with CD14, while no response was seen when the cells were transfected with TLR4/MD-2 alone. These data indicate that TLR4/MD-2 was not only responsible for the CD14 effects, but also completely dependent on CD14 in order to induce the cytokine response. LPS is a main exogenous ligand for CD14/TLR4/MD-2 and is highly dependent on CD14 (Fitzgerald et al., 2004). Endogenous ligands are also candidates for CD14 recognition. Thus, in a recent study 
by Kaczorowski et al., mice deficient in CD14 showed a significantly lower IL-6 and MCP-1 response during cold ischemia/reperfusion injury in the heart (Kaczorowski et al., 2009). Our findings indicate that there are substances in meconium that are recognized by CD14 before transferred to the TLR4/MD-2 complex. The TLR2mediated activation of NF- $\mathrm{B}$ B was negligible whether or not CD14 was expressed.

Meconium is accumulated in the bowel of the fetus and is suggested to be sterile together with the gastrointestinal tract of the fetus (Mackie et al., 1999). The prevalence of positive amniotic fluid cultures, however, was significantly higher in women with meconium-stained amniotic fluid and intact membranes than in women with clear fluid (Romero et al., 2006). Jimenez et al identified Enterococcus fecalis in 17 of 21 meconium samples from healthy newborns and Staphylococcus epidermidis in 10 of the samples (Jimenez et al., 2008). Thus, contamination of meconium by bacterial products including LPS should be carefully considered. In the present study the LPS content of the meconium was $30 \mathrm{EU} / \mathrm{mg}$ meconium (or $3 \mathrm{ng} / \mathrm{mg}$ meconium; cfr. Methods). We have earlier investigated the role of LPS in meconium-induced cytokine formation (Salvesen et al., 2008) by comparing meconium-induced and LPSinduced cytokine formation in human whole blood. The cytokine formation induced by meconium containing $20 \mathrm{pg} \mathrm{LPS} / \mathrm{mg}$, at $1 \mathrm{mg}$ meconium $/ \mathrm{mL}$ whole blood, was considerably higher than that induced by LPS at concentration up to $10 \mathrm{ng} / \mathrm{mL}$ whole blood (Salvesen et al., 2008). In the present study we found a higher LPS content of meconium than in the former, most likely reflecting the different LPS-assays used. We therefore in the present study also compared LPS and meconium-induced proinflammatory cytokine formation in "LPS-equivalent" doses (data not shown). There was a dose-dependent increased formation of TNF $\alpha$, IL-1 $\beta$, IL-6 and IL- 8 with 
increasing concentrations of meconium and LPS, respectively, but the meconiuminduced cytokine formation was 5-15 folds higher compared to the increase seen with equivalent doses of LPS. The relative difference increased with increasing concentrations of meconium. We therefore conclude that LPS, although contributing to a certain extent, could not explain the meconium-induced inflammatory reaction. Meconium, however, contains innumerable agents which are candidates for endogenous danger signaling, in particular since it contains "damaged self". Cell surface TLRs are known to respond to many endogenous ligands like heparan sulfate, hyaluronan, biglycans, fibrinogen, surfactant protein A, fibronectin , HMGB1 and $\beta$ defensin (Levy et al., 2006;Miyake, 2007). We therefore suggest that the inflammatory response induced by meconium is mainly mediated by endogenous ligands, although the candidate substances are currently unknown.

In the present study meconium induced formation of 21 of 27 mediators measured. This is in accordance with our previous study documenting a massive cytokine response induced by meconium (Salvesen et al., 2008). The potency of meconium to induce an inflammatory reaction is reflected in the clinical picture of MAS which is associated both with a chemical pneumonitis and a systemic inflammatory response. Notably, many of the inflammatory mediators found in our in vitro study are the same as those measured in neonates with known MAS (Okazaki et al., 2008), suggesting that our model is relevant as in vitro model for the inflammatory reaction induced in MAS.

Although the incidence of severe MAS has declined in western countries probably because of fewer post-term deliveries (Dargaville and Copnell, 2006), MAS is still a 
severe condition with no specific treatment. The pathophysiology needs further investigations. The present study suggests that meconium contains substances that activate the TLR4/MD-2 complex mainly by endogenous mechanisms, dependent on CD14. The TLR4/MD-2 antagonist CyP reduced meconium-induced inflammation almost to the same extent as anti-CD14. Inhibitors of CD14/TLR4/MD-2, including $\mathrm{CyP}$, may be therapeutic candidates to attenuate the inflammatory reaction in MAS:

\section{Acknowledgements}

We thank Anne Pharo for performing the LAL assay. This project was financially supported by The Research Council of Norway. 


\section{REFERENCES}

1. Antonowicz,I., Shwachman,H., 1979. Meconium in health and in disease. Adv. Pediatr. 26, 275-310.

2. Castellheim,A., Lindenskov,P.H., Pharo,A., Fung,M., Saugstad,O.D., Mollnes,T.E., 2004. Meconium is a potent activator of complement in human serum and in piglets. Pediatr. Res. 55, 310-318.

3. Chow,J.C., Young,D.W., Golenbock,D.T., Christ,W.J., Gusovsky,F., 1999. Toll-like receptor-4 mediates lipopolysaccharide-induced signal transduction. J. Biol. Chem. 274, 10689-10692.

4. Cleary,G.M., Wiswell,T.E., 1998. Meconium-stained amniotic fluid and the meconium aspiration syndrome. An update. Pediatr. Clin. North Am. 45, 511 529.

5. Dargaville,P.A., Copnell,B., 2006. The epidemiology of meconium aspiration syndrome: incidence, risk factors, therapies, and outcome. Pediatrics 117, 17121721.

6. Fitzgerald,K.A., Rowe,D.C., Golenbock,D.T., 2004. Endotoxin recognition and signal transduction by the TLR4/MD2-complex. Microbes. Infect. 6, 1361-1367.

7. Gay,N.J., Gangloff,M., 2007. Structure and function of Toll receptors and their ligands. Annu. Rev. Biochem. 76, 141-165.

8. Hellerud,B.C., Stenvik,J., Espevik,T., Lambris,J.D., Mollnes,T.E., Brandtzaeg,P., 2008. Stages of meningococcal sepsis simulated in vitro, with emphasis on complement and Toll-like receptor activation. Infect. Immun. 76, 4183-4189.

9. Janeway,C.A., Jr., Medzhitov,R., 2002. Innate immune recognition. Annu. Rev. Immunol. 20, 197-216.

10. Jemmett,K., Macagno,A., Molteni,M., Heckels,J.E., Rossetti,C., Christodoulides,M., 2008. A cyanobacterial lipopolysaccharide antagonist inhibits cytokine production induced by Neisseria meningitidis in a human whole-blood model of septicemia. Infect. Immun. 76, 3156-3163.

11. Jimenez,E., Marin,M.L., Martin,R., Odriozola,J.M., Olivares,M., Xaus,J., Fernandez,L., Rodriguez,J.M., 2008. Is meconium from healthy newborns actually sterile? Res. Microbiol.

12. Kaczorowski,D.J., Nakao,A., Vallabhaneni,R., Mollen,K.P., Sugimoto,R., Kohmoto,J., Zuckerbraun,B.S., McCurry,K.R., Billiar,T.R., 2009. Mechanisms of Toll-like receptor 4 (TLR4)-mediated inflammation after cold ischemia/reperfusion in the heart. Transplantation 87, 1455-1463. 
13. Kawai,T., Akira,S., 2009. The roles of TLRs, RLRs and NLRs in pathogen recognition. Int. Immunol.

14. Lee,H.K., Dunzendorfer,S., Soldau,K., Tobias,P.S., 2006. Double-stranded RNA-mediated TLR3 activation is enhanced by CD14. Immunity. 24, 153-163.

15. Levy,R.M., Prince,J.M., Yang,R., Mollen,K.P., Liao,H., Watson,G.A., Fink,M.P., Vodovotz,Y., Billiar,T.R., 2006. Systemic inflammation and remote organ damage following bilateral femur fracture requires Toll-like receptor 4. Am. J. Physiol Regul. Integr. Comp Physiol 291, R970-R976.

16. Macagno,A., Molteni,M., Rinaldi,A., Bertoni,F., Lanzavecchia,A., Rossetti,C., Sallusto,F., 2006. A cyanobacterial LPS antagonist prevents endotoxin shock and blocks sustained TLR4 stimulation required for cytokine expression. J. Exp. Med. 203, 1481-1492.

17. Mackie,R.I., Sghir,A., Gaskins,H.R., 1999. Developmental microbial ecology of the neonatal gastrointestinal tract. Am. J. Clin. Nutr. 69, 1035S-1045S.

18. Matzinger,P., 1994. Tolerance, danger, and the extended family. Annu. Rev. Immunol. 12, 991-1045.

19. Medzhitov,R., Janeway,C., Jr., 2000. The Toll receptor family and microbial recognition. Trends Microbiol. 8, 452-456.

20. Miyake,K., 2007. Innate immune sensing of pathogens and danger signals by cell surface Toll-like receptors. Semin. Immunol. 19, 3-10.

21. Mollnes,T.E., Brekke,O.L., Fung,M., Fure,H., Christiansen,D., Bergseth,G., Videm,V., Lappegard,K.T., Kohl,J., Lambris,J.D., 2002. Essential role of the C5a receptor in E coli-induced oxidative burst and phagocytosis revealed by a novel lepirudin-based human whole blood model of inflammation. Blood 100, 1869-1877.

22. Mollnes,T.E., Castellheim,A., Lindenskov,P.H., Salvesen,B., Saugstad,O.D., 2008. The role of complement in meconium aspiration syndrome. J. Perinatol. 28 Suppl 3, S116-S119.

23. Muta,T., Takeshige,K., 2001. Essential roles of CD14 and lipopolysaccharidebinding protein for activation of toll-like receptor (TLR)2 as well as TLR4 Reconstitution of. Eur. J. Biochem. 268, 4580-4589.

24. Nagai,Y., Akashi,S., Nagafuku,M., Ogata,M., Iwakura,Y., Akira,S., Kitamura,T., Kosugi,A., Kimoto,M., Miyake,K., 2002. Essential role of MD-2 in LPS responsiveness and TLR4 distribution. Nat. Immunol. 3, 667-672.

25. Nilsen,N.J., Deininger,S., Nonstad,U., Skjeldal,F., Husebye,H., Rodionov,D., von,A.S., Hartung,T., Lien,E., Bakke,O., Espevik,T., 2008. Cellular trafficking of lipoteichoic acid and Toll-like receptor 2 in relation to signaling: role of CD14 and CD36. J. Leukoc. Biol. 84, 280-291. 
26. Okazaki,K., Kondo,M., Kato,M., Kakinuma,R., Nishida,A., Noda,M., Taniguchi,K., Kimura,H., 2008. Serum cytokine and chemokine profiles in neonates with meconium aspiration syndrome. Pediatrics 121, e 748-e753.

27. Perera,P.Y., Vogel,S.N., Detore,G.R., Haziot,A., Goyert,S.M., 1997. CD14dependent and CD14-independent signaling pathways in murine macrophages from normal and CD14 knockout mice stimulated with lipopolysaccharide or taxol. J. Immunol. 158, 4422-4429.

28. Romero,R., Espinoza,J., Goncalves,L.F., Kusanovic,J.P., Friel,L.A., Nien,J.K., 2006. Inflammation in preterm and term labour and delivery. Semin. Fetal Neonatal Med. 11, 317-326.

29. Salvesen,B., Fung,M., Saugstad,O.D., Mollnes,T.E., 2008. Role of Complement and CD14 in Meconium-Induced Cytokine Formation. Pediatrics 121, e496e505.

30. Salvesen,B., Nielsen,E.W., Harboe,M., Saugstad,O.D., Mollnes,T.E., 2009. Mechanisms of complement activation and effects of $\mathrm{C} 1$-inhibitor on the meconium-induced inflammatory reaction in human cord blood. Mol. Immunol. 46, 688-694.

31. Seong,S.Y., Matzinger,P., 2004. Hydrophobicity: an ancient damage-associated molecular pattern that initiates innate immune responses. Nat. Rev. Immunol. 4, 469-478.

32. Shimazu,R., Akashi,S., Ogata,H., Nagai,Y., Fukudome,K., Miyake,K., Kimoto,M., 1999. MD-2, a molecule that confers lipopolysaccharide responsiveness on Toll-like receptor 4. J. Exp. Med. 189, 1777-1782.

33. Thorgersen,E.B., Macagno,A., Rossetti,C., Mollnes,T.E., 2008. Cyanobacterial LPS antagonist (CyP)-A novel and efficient inhibitor of Escherichia coli LPSinduced cytokine response in the pig. Mol. Immunol.

34. Uthaisangsook,S., Day,N.K., Bahna,S.L., Good,R.A., Haraguchi,S., 2002. Innate immunity and its role against infections. Ann. Allergy Asthma Immunol. $88,253-264$.

35. Viriyakosol,S., Kirkland,T., Soldau,K., Tobias,P., 2000. MD-2 binds to bacterial lipopolysaccharide. J. Endotoxin. Res. 6, 489-491. 


\section{FIGURE LEGENDS}

\section{Figure 1}

\section{Dose-dependent effect of CyP on meconium-induced inflammation}

Human whole blood was preincubated with increasing concentrations of CyP from $0.156-20 \mu \mathrm{g} / \mathrm{mL}$ blood until meconium $1 \mathrm{mg} / \mathrm{mL}$ was added and then incubated for four hours. Increasing concentrations of $\mathrm{CyP}$, dose-dependently reduced the meconium-induced formation of TNF- $\alpha$, IL- 6 , IFN- $\gamma$ and IL-8. Data are presented as means with range from experiments using blood from two different donors.

\section{Figure 2}

\section{Effect of CyP on inflammation induced by different doses of meconium}

Human whole blood was incubated with increasing concentrations of meconium from 0.003 to $1 \mathrm{mg} / \mathrm{mL}$ blood for four hours. Increasing concentrations of meconium, dosedependently increased meconium-induced formation of TNF- $\alpha$, IL-1 $\beta$, IL-6 and IL-8 (closed circles), whereas CyP efficiently reduced this formation (open circles). Data are presented as means with range from experiments using blood from two different donors.

\section{Figure 3}

Effect of CyP and anti-CD14 on meconium-induced formation of pro- and antiinflammatory cytokines

Human whole blood preincubated with CyP, anti-CD14 (a14) or an isotype matched control antibody (Ctr.) was incubated with meconium (Mec) $0.1 \mathrm{mg} / \mathrm{mL}$ blood for four 
hours. B (baseline) = blood incubated for four hours with buffer only. Meconiuminduced formation of the proinflammatory cytokines TNF- $\alpha$, IL-1 $\beta$, IL-6, IFN- $\gamma$ and the anti-inflammatory cytokines IL-10 and Il-1Ra were measured. Data are presented as means with $95 \% \mathrm{CI}$ of experiments using blood from 6 different donors. $*=p<$ 0.001 compared with meconium alone.

\section{Figure 4}

The Effect of CyP and anti-CD14 on meconium-induced inflammation formation of chemokines

Human whole blood preincubated with CyP, anti-CD14 (a14) or an isotype matched control antibody (Ctr.) was incubated with meconium (Mec) $0.1 \mathrm{mg} / \mathrm{mL}$ blood for four hours. B (baseline) = blood incubated for four hours with buffer only. Meconiuminduced formation of the chemokines Il-8, MCP-1, MIP-1 $\alpha$, MIP-1 $\beta$, eotaxin and IP10 were measured. Data are presented as means with 95\% CI of experiments using blood from 6 different donors. $*=p<0.001$ compared with meconium alone.

\section{Figure 5}

\section{The Effect of CyP and aCD14 on meconium-induced inflamation formation of growth factors}

Human whole blood preincubated with CyP, anti-CD14 (a14) or an isotype matched control antibody (Ctr.) was incubated with meconium (Mec) $0.1 \mathrm{mg} / \mathrm{mL}$ blood for four hours. B (baseline) = blood incubated for four hours with buffer only. Meconiuminduced formation of the growth factors G-CSF, GM-CSF, basic FGF and PDGFbb were measured. Data are presented as means with $95 \%$ CI of experiments using blood 
from 6 different donors. $*=\mathrm{p}<0.001$ compared with meconium alone for G-CSF, GM-CSF and basic FGF, and $\mathrm{p}=0.003$ for PDGFbb.

\section{Figure 6}

\section{Activation of NF- $k$ B by meconium in transfected HEK293 cells}

Relative induction (means and SD) of NF- $k$ B in HEK293 cells transiently transfected with NF- $k$ B luciferase and TLR4/MD2 alone or in combination with CD14 (left panel), NF- $k$ B luciferase and TLR2 alone or in combination with CD14 (middle panel) and NF- $k$ B luciferase and TLR9 (right panel). The highest sample concentrations during treatment $\left(10^{-1}\right.$ dilution) were $100 \mathrm{ug} / \mathrm{mL}$ meconium, $1 \mathrm{ug} / \mathrm{ml}$ LPS (positive control for TLR4/MD-2/CD14) and 0.5ug/mL FSL-1 (positive control for TLR2/CD14). For TLR9 the cells were treated with 10uM CpG (positive control) and $100 \mathrm{ug} / \mathrm{mL}$ meconium. 


\section{Titration of CyP}

TNF- $\alpha$

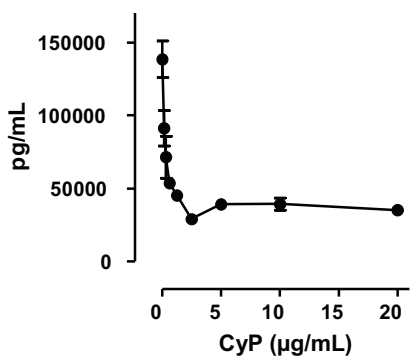

IFN-Y

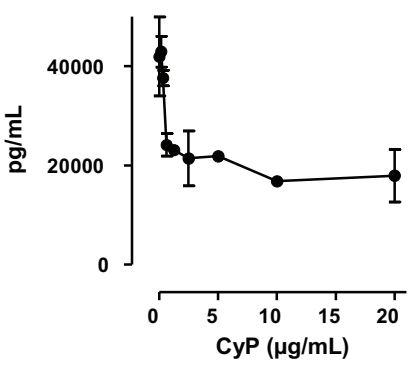

IL-6

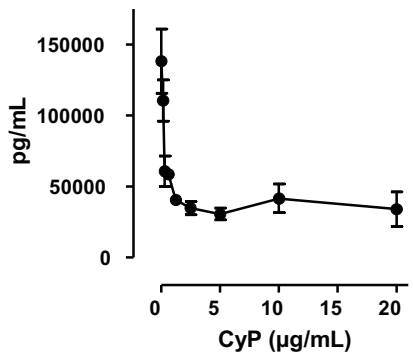

IL-8

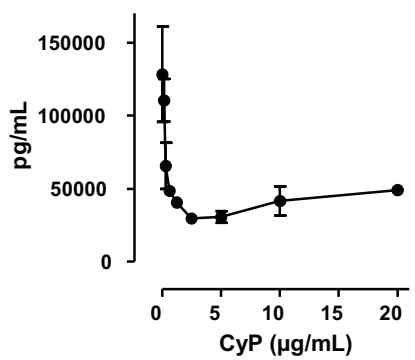



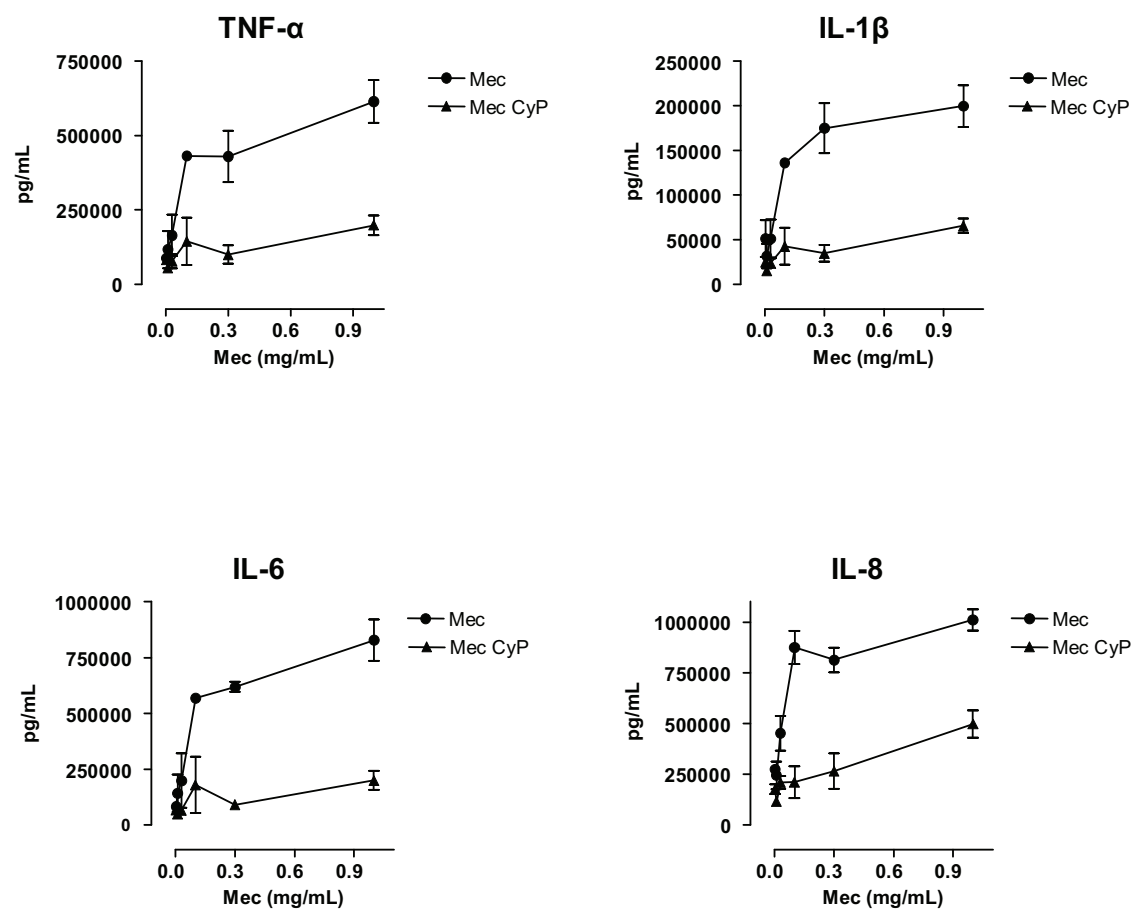
Figure 3

\section{Pro and anti-inflammatory cytokines}
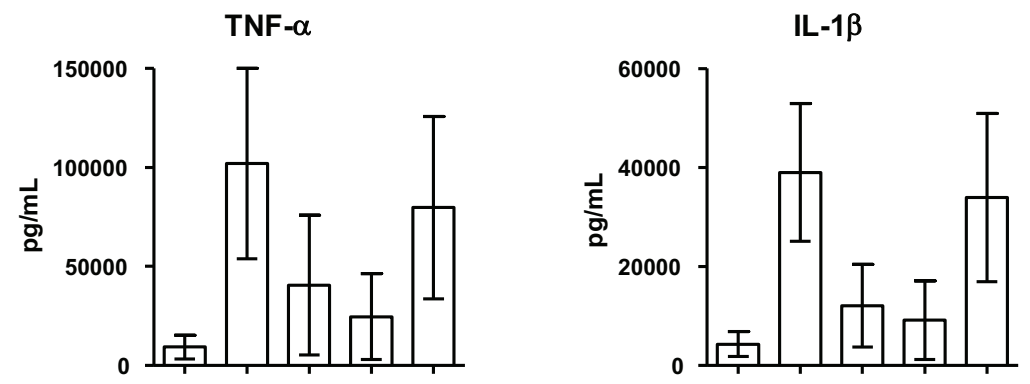

IL-6

IFN- $\gamma$
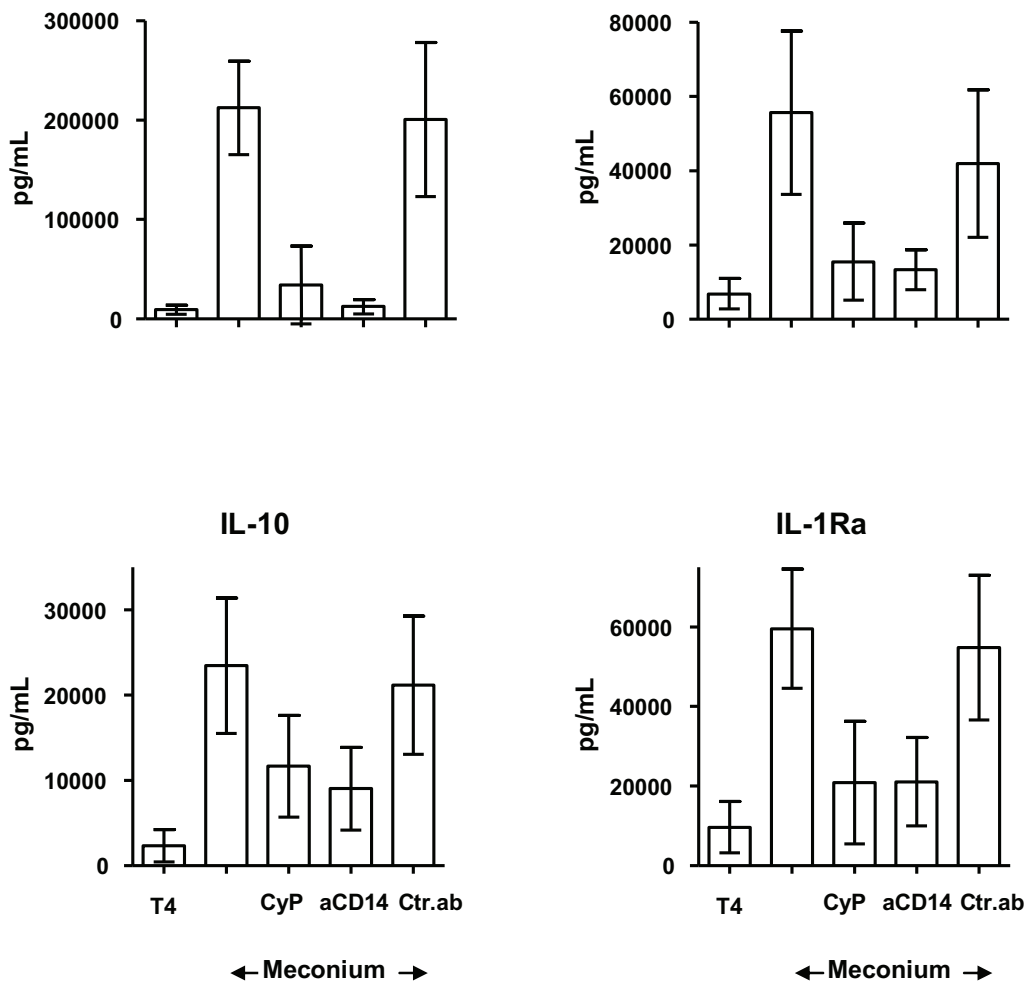


\section{Chemokines}
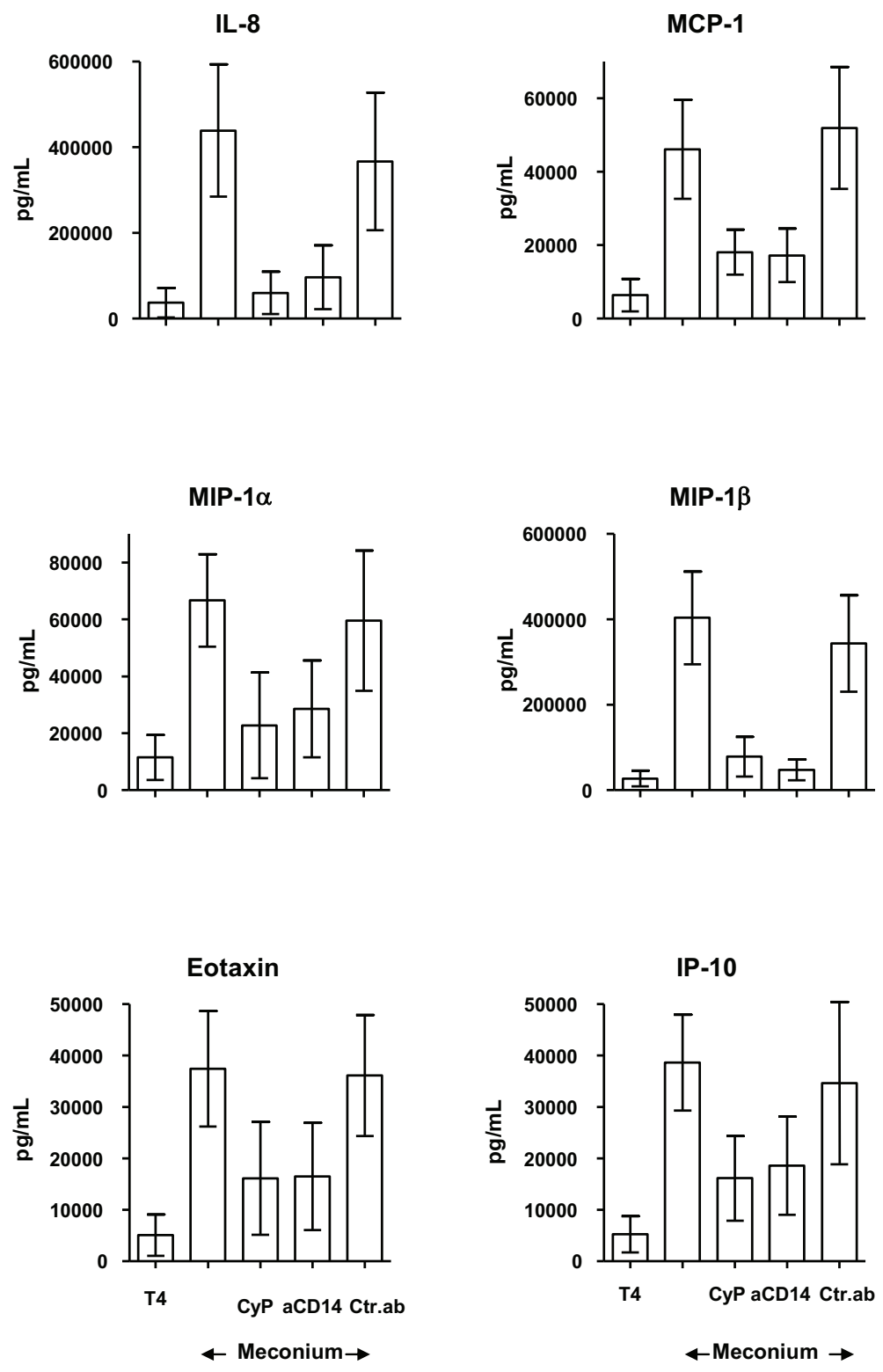
Figure 5

\section{Growth factors}
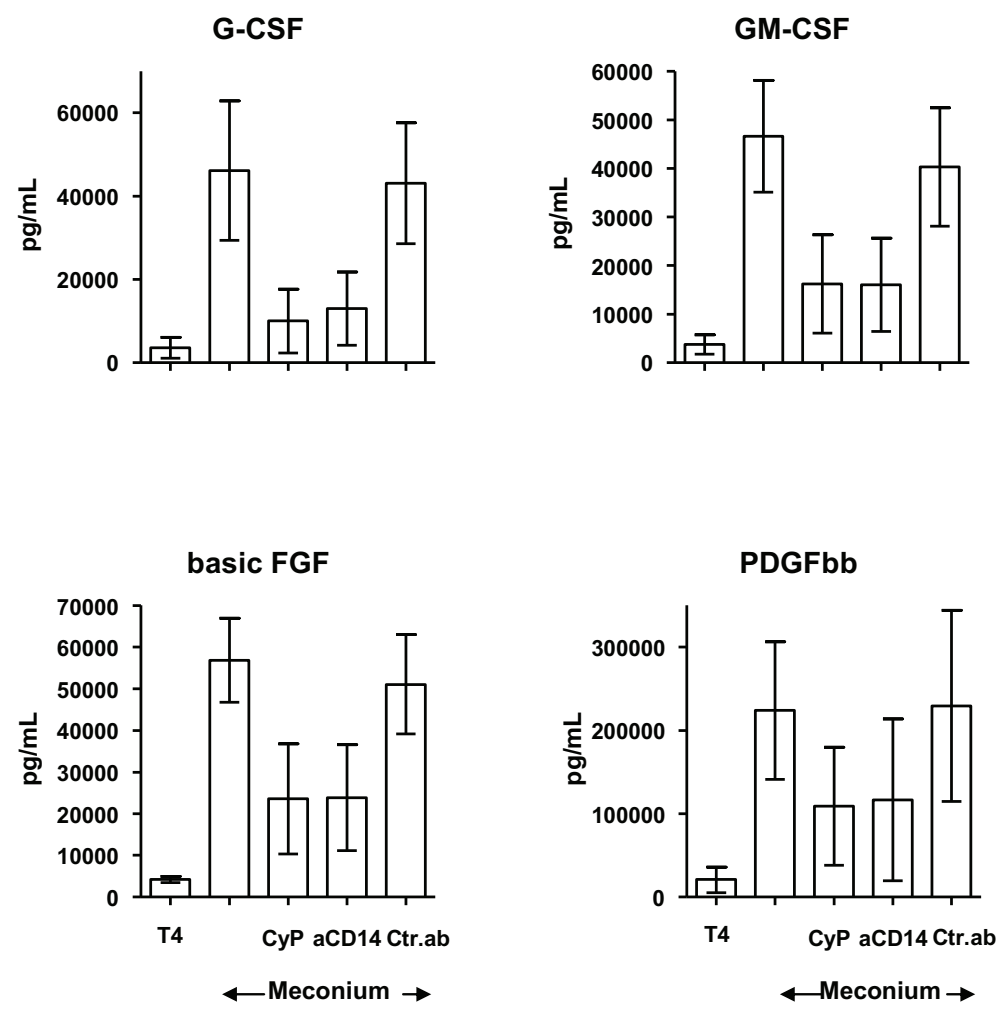
Figure 6

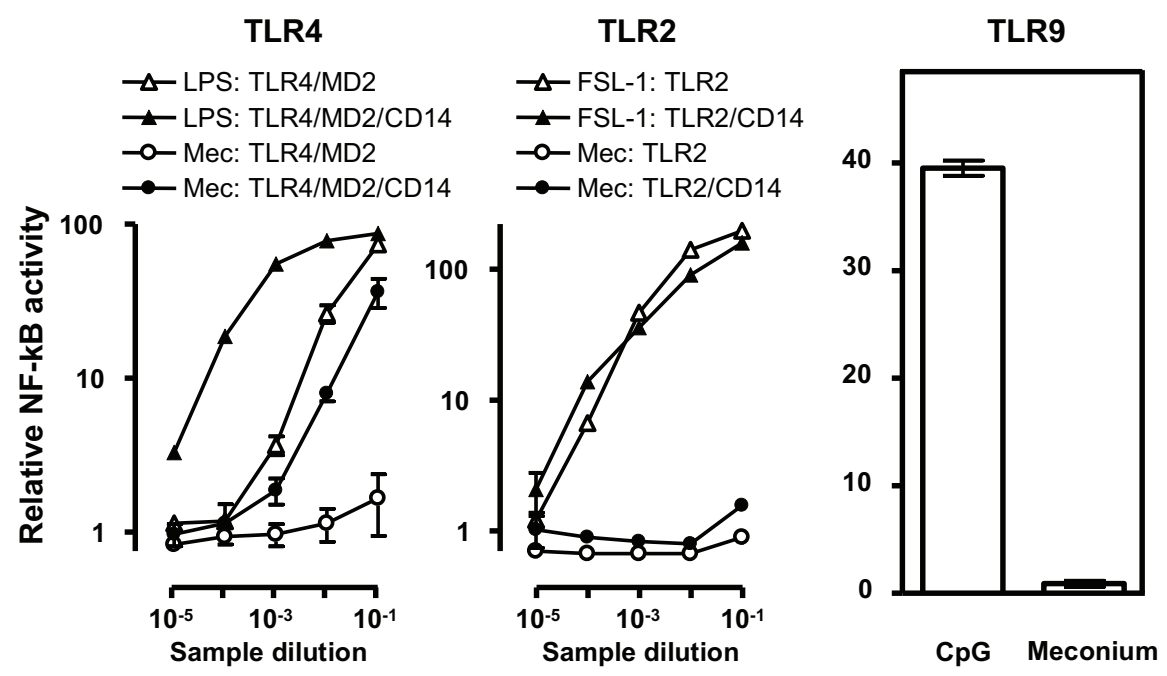



This article is removed. 
